Bentham open
CrossMark
Content list available at: www.benthamopen.com/TOMCJ/
DOI: $10.2174 / 1874104501711010222$

RESEARCH ARTICLE

\title{
Intra Nasal In situ Gelling System of Lamotrigine Using Ion Activated Mucoadhesive Polymer
}

\author{
Asha Paul, K.M .Fathima and Sreeja C. Nair ${ }^{*}$ \\ Department of Pharmaceutics, Amrita School of Pharmacy, Amrita Vishwa Vidyapeetham, Amrita University, AIMS \\ Health Science Campus, Kochi, India
}

Received: September 2, 2017

Revised: December 11, 2017

Accepted: December 12, 2017

\begin{abstract}
:
Background:

A novel drug delivery system for treating acute epileptic condition.
\end{abstract}

\section{Objective:}

To develop an intranasal mucoadhesive formulation of Lamotrigine (LTG) loaded insitu gel, for the treatment of epilepsy to avoid possible side effects and first pass metabolism associated with conventional treatment.

\section{Methods:}

Lamotrigine was loaded into different polymeric solutions of gellan and xanthan gum.

\section{Results:}

All formulations subjected to various evaluation studies were within their acceptable limits. The $\mathrm{pH}$ of formulation ranges between $5.8 \pm .001$ to $6.8 \pm .005$ indicating that no mucosal irritation is expected as $\mathrm{pH}$ was in acceptable range. Invitro drug release from the mucoadhesive insitu gel formulations showed immediate drug release pattern with a maximum drug release of $97.02 \pm 0.54 \%$ for optimized G5 formulation within 20min. Exvivo permeation studies of optimized formulation G5 and control formulation was estimated. Exvivo permeation studies of G5 insitu formulation done for a period of $12 \mathrm{~h}$ resulted in slow, sustained release and greater permeability significance $(\mathrm{P}<0.05)$ through nasal mucosa when compared to control. Histopathological studies showed that G5 formulation was safer for nasal administration without any irritation. The stability studies indicated that gels were stable over 45 days in refrigerated condition $\left(4 \pm 2^{\circ} \mathrm{C}\right)$.

\section{Conclusion:}

The intranasal insitu gelling system is a promising novel drug delivery system for an antiepileptic drug lamotrigine which could enhance nasal residence time with increased viscosity and mucoadhesive character and provided better release profile of drug for treating acute epileptic conditions.

Keywords: Intranasal formulation, Mucoadhesion, Insitu gel, Immediate release, Acute epileptic condition, Ex vivo permeation.

\section{INTRODUCTION}

Epilepsy is a neurological disorder of brain characterized by sudden recurrent episodes of sensory disturbances with brief loss of consciousness and awareness, which ultimately lead to seizures. Epileptic seizures are undetectable and can vary from short to long periods of vigorous shaking, to loss of body functions and motor functions and to mood swings.

\footnotetext{
* Address correspondence to this author at the Department of Pharmaceutics, Amrita School of Pharmacy, Amrita Vishwa Vidyapeetham, Amrita University, AIMS Health Science Campus, Kochi, India, Tel: 09388600399; E-mail: sreejacnair@aims.amrita.edu
} 
In epilepsy, seizures tend to recur and have no immediate underlying cause [1]. Epileptic seizures are the result of excessive and abnormal nerve cell activity in the cortex of the brain. Pathophysiology of epilepsy is partially understood [2]. Some occur as a result of tumour of brain, brain injury and brain defect stroke. About 50 million people have epilepsy worldwide. Seizures can be controlled with medication in about $70 \%$ cases otherwise surgery, dietary changes and neurostimulation should be considered. AEDs (Antiepileptic drugs) are the medications used in the treatment of epileptic seizure, some of them act by targeting the voltage gated $\mathrm{Na}^{+}$(sodium) and $\mathrm{Ca}^{+}$(calcium) channel while some act in stimulating GABA system. Selection of AED for a patient depends upon the affected individual's condition and side effects of drug. This article mainly helps in evaluating and developing an insitu gel loaded with lamotrigine. The reason for selecting intranasal insitu drug delivery is because of its large surface area for drug absorption, as it avoids first pass metabolism and it help in delivering drug to CNS thereby by passing BBB, there is rapid onset of pharmacological action and higher bioavailability of lipophilic drugs like lamotrigine. Insitu delivery system favours the ease and convenience of administration as drops allowing accurate dosing. Mucoadhesive system aims in targeting and localization of the dosage forms and provide an intimate contact between dosage form and absorptive mucosa resulting in high drug flux at the absorbing tissue. It's a novel drug delivery system since lamotrigine was only available as tablet (chewable, disintegrating, extended release) and IV formulation. Intranasal insitu gel is developed for the purpose of immediate release of lamotrigine for treating acute epileptic condition, which is very essential in treating an emergency condition [3 - 24].

\section{METHODOLOGY}

\subsection{Materials}

Lamotrigine was provided as a gift sample by Auro Bindo Pharma private limited, Hyderabad. Gellan gum was obtained from Marine Hydrocolloids, Kochi. Dialysis membrane (12000-14000 mol. Wt. Cut off) was procured from Sigma Aldrich.

\subsection{Preformulation Studies}

Preformulation investigations are intended to convey all essential data, especially physico-chemical, physicomechanical and biopharmaceutical properties of drug substances and its excipients as well as its compatibility.

\subsubsection{Identification of Drug}

\subsubsection{Fourier transform infrared (FTIR) spectroscopy [25-27]}

FTIR spectrum of the obtained pure drug of Lamotrigine was compared with the FTIR of the standard drug spectrum (from monograph, IP). FTIR spectrum was obtained by using FTIR spectrophotometer by KBr (potassium bromide) pellet method.

\subsubsection{Solubility Studies [28, 29]}

Solubility studies of drug lamotrigine) was determined in different solvents such as water, ethanol, methanol, 1propanol, acetone and 1-butanol and in phosphate buffer (PBS) pH 6.6 to find the solvent in which lamotrigine is completely soluble, so as to give a better absorption curve of lamotrigine in UV spectrophotometer.

\subsubsection{Melting Point [30, 31$]$}

The purity of the sample is indicated by its melting point. The presence of relative slight amount of impurity will decrease the melting point. Open capillary method was used to determine the melting point of sample.

\subsubsection{Partition Coefficient [32,33]}

Partition coefficient of Lamotrigine in n-octanol water was determined. Equal volumes of water and n-Octanol were taken in a separating funnel, and known amount of lamotrigine was added in it. For $2 \mathrm{~h}$ at constant temperature the funnel was vigoursly shaken at regular intervals. Then the amount of drug in aqueous layer was determined by UV spectroscopy (Ultra Violet Spectroscopy) at 309nm (Nano meter). The n-octanol partition coefficient of the drug was obtained using the following equation:

Partition coefficient $=$ Concentration of drug in organic layer/ Concentration of drug in aqueous phase. 


\subsubsection{5.. Lamda Max $\left(\kappa_{\text {max }}\right)$ of Lamotrigine in Methanol [34]}

Absorption maxima of lamotrigine was determined in solvent methanol. Standard stock solution is prepared by dissolving 10mg (Milligram) of lamotrigine in 30ml (Millilitre) methanol by sonication for 10 minutes and volume was made up to $100 \mathrm{ml}$ mark using methanol. The concentration of standard stock solution is $100 \mu \mathrm{g} / \mathrm{ml}(\mathrm{Microgram}$ per millilitre). This was scanned from 400-200nm by using UV spectrophotometer.

\subsubsection{Lamda Max of Lamotrigine in PBS pH 6.6}

Absorption maxima of lamotrigine was determined in solvent PBS pH 6.6. Standard stock solution was prepared by dissolving $10 \mathrm{mg}$ of lamotrigine in $30 \mathrm{ml}$ PBS pH 6.6 by sonication for 10 minutes and volume was made up to $100 \mathrm{ml}$ mark using PBS pH 6.6. The concentration of standard stock solution was $100 \mu \mathrm{g} / \mathrm{ml}$. This was scanned from 400-200nm by using UV spectrophotometer.

\subsubsection{Compatibility Studies of Drug Lamotrigine with the Excipients [35, 36]}

It is very important to carefully select the excipients to develop an effective, stable and optimised dosage form to facilitate easy administration, promote the better release and bioavailability of drug and to protect it from degradation. The compatibility study of drug lamotrigine and excipients is very important. The drug excipient compatibility study was performed by preparing a homogenous physical mixture of drug and all possible excipients to be used in formulation in the ratio 1:1. FTIR spectra of drug and excipients were obtained to ascertain the compatibility between lamotrigine and selected polymers using FT infrared spectrophotometer by KBr pellet method.

\subsubsection{X-ray Diffraction Studies (XRD) [37-39]}

XRD studies are the most powerful and established technique for material structural analysis, capable of providing information about the structure of a material at its atomic level. X-Ray diffraction studies pattern was recorded for a specified quantity of pure drug and optimised formulation (G5) on X-ray diffractometer (Model -Bruker AXS D8 advance, Configuration - Vertical theta $/ 2$ theta geometry, Angle range - 360 ${ }^{\circ}$, X Ray source - Cu, Wavelength - 1.5406 ${ }^{\circ} \mathrm{A}$, Detector $-\mathrm{Si}(\mathrm{Li}) \mathrm{PSD}$, Temperature range $-170^{\circ} \mathrm{C}-450^{\circ} \mathrm{C}$ ). The XRD pattern of insitu gel formulation was compared with that of the pure drug.

\subsubsection{Analytical Methods}

Calibration curve was done using methanol and PBS pH 6.6.

\subsubsection{Calibration Curve of Lamotrigine in Methanol [40]}

a. Preparation of standard stock solution

$10 \mathrm{mg}$ of lamotrigine in $30 \mathrm{ml}$ of methanol was sonicated for 10 minutes and the volume was made up to $100 \mathrm{ml}$ mark using methanol. The drug was dissolved and diluted with methanol to get concentration of $100 \mu \mathrm{g} / \mathrm{ml}$.

b. Preparation of standard graph

From this stock solution $(100 \mu \mathrm{g}($ microgram $))$ different aliquots $0.5 \mathrm{ml}, 1 \mathrm{ml}, 1.5 \mathrm{ml}, 2 \mathrm{ml}$ and $2.5 \mathrm{ml}$ were drawn and diluted to $10 \mathrm{ml}$ with methanol separately to prepare a series of concentration from range $5-30 \mu \mathrm{glml}$. The standard stock solution $(100 \mu \mathrm{glml})$ was scanned in the range of $400-200 \mathrm{~nm}$ against methanol as blank. Standard graph was obtained by plotting absorbance against concentration $(\mu \mathrm{g} / \mathrm{ml})$.

\subsubsection{Calibration Curve of Lamotrigine in PBS pH 6.6}

a. Preparation of PBS pH 6.6 solution $2.712 \mathrm{~g}$ (gram) of potassium dihydogen ortho phosphate was dissolved in $100 \mathrm{ml}$ distilled water and $0.8 \mathrm{~g}$ of sodium hydroxide $(\mathrm{NaOH})$ was dissolved in $100 \mathrm{ml}$ distilled water separately. From the prepared solutions, $25 \mathrm{ml}$ of potassium dihydogen ortho phosphate and $8.2 \mathrm{ml}$ of $\mathrm{NaOH}$ were pipetted into $100 \mathrm{ml}$ standard flask and volume was made up to $100 \mathrm{ml}$ mark using distilled water.

b. Preparation of standard stock solution $10 \mathrm{mg}$ of lamotrigine in $30 \mathrm{ml}$ of phosphate buffer was sonicated for 10 minutes and the volume was made up to $100 \mathrm{ml}$ mark using PBS. Using PBS the drug was dissolved and diluted to get a concentration of $100 \mu \mathrm{glml}$.

c. Preparation of standard graph 
From this stock solution $(100 \mu \mathrm{g})$ different aliquots were drawn and diluted to $10 \mathrm{ml}$ with PBS separately to prepare a series of concentration from range $5-30 \mu \mathrm{glml}$. The standard stock solution $(100 \mu \mathrm{glml})$ was scanned in the range of 400-200nm against PBS as blank. Standard graph was obtained by plotting absorbance against concentration $(\mu \mathrm{g} / \mathrm{ml})$.

\subsection{Formulation of Intra Nasal In situ Gel of Lamotrigine [41 - 49]}

Polymeric solution of gellan gum and xanthan gum was prepared using deionised water and mixed with mechanical stirrer for $2 \mathrm{~min}$. Preservatives, such as ethyl paraben, mannitol and Polyethylene glycol (PEG), were added into polymeric solutions, and then kept in a water bath for few minutes. Then, it was cooled to room temperature. Drug was then mixed with small amount of methanol and then sonicated. Drug solution was added to beaker containing polymeric mixture which was then continuously stirred until the entire drug was dissolved. The prepared formulation was transferred to a clean glass container which was made up to $10 \mathrm{ml}$ volume with distilled water and stored in a cool place. Table 1 gives the composition of insitu gel of lamotrigine.

Table 1. Composition of different formulation of intra nasal insitu gel of Lamotrigine.

\begin{tabular}{|c|c|c|c|c|c|c|c|}
\hline SL.NO. & FORMULATION & $\begin{array}{c}\text { LAMOTRIGINE } \\
\text { (DRUG) \%w/v }\end{array}$ & GELLAN GUM \%w/v $\mathbf{v}$ & $\begin{array}{c}\text { XANTHAN } \\
\mathbf{G U M} \\
\mathbf{\%} \mathbf{w} / \mathbf{v}\end{array}$ & $\begin{array}{c}\text { MANNITOL } \\
\mathbf{\%} \mathbf{w} / \mathbf{v}\end{array}$ & PEG\%w/v & ETHYL PARABEN \%w/v \\
\hline 1 & $\mathbf{G}_{\mathbf{1}}$ & 0.2 & 0.5 & 0.25 & 0.15 & 0.2 & 0.10 \\
\hline 2 & $\mathbf{G}_{\mathbf{2}}$ & 0.2 & 0.75 & 0.25 & 0.15 & 0.2 & 0.10 \\
\hline 3 & $\mathbf{G}_{\mathbf{3}}$ & 0.2 & 1.0 & 0.25 & 0.15 & 0.2 & 0.10 \\
\hline 4 & $\mathbf{G}_{\mathbf{4}}$ & 0.2 & 1.25 & 0.25 & 0.15 & 0.2 & 0.10 \\
\hline 5 & $\mathbf{G}_{\mathbf{5}}$ & 0.2 & 1.5 & 0.25 & 0.15 & 0.2 & 0.10 \\
\hline 6 & $\mathbf{G}_{\mathbf{6}}$ & 0.2 & 1.75 & 0.25 & 0.15 & 0.2 & 0.10 \\
\hline 7 & $\mathbf{G}_{\mathbf{7}}$ & 0.2 & 2.0 & 0.25 & 0.15 & 0.2 & 0.10 \\
\hline
\end{tabular}

2.4. Characterisation of Intranasal In situ Gel

\subsubsection{Physiochemical Properties}

\subsubsection{Homogeneity Studies}

All the prepared formulations were inspected for homogeneity studies by visually observing the appearance and the presence of lumps in the formulation.

\subsubsection{Gelling time $[50,51]$}

The system exists in sol form before administration and after administration it turns into gel form. Gelling time is the time taken for the transformation of sol to gel form. Time for gelation is recorded by placing $2 \mathrm{ml}$ of prepared solution in a test tube and adding small amount of simulated nasal fluid, maintaining the temperature at $37^{\circ} \mathrm{C}$ and visually observing the gel formation, and onset of time for gelation is recorded as gelling time in seconds.

\subsubsection{Syringeability}

Syringeablity test was performed by transferring freshly prepared formulations into an identical $5 \mathrm{ml}$ plastic syringe placed with 20 gauge needle to a constant volume $(1 \mathrm{ml})$. The solutions which were easily passed from syringe weretermed as pass and difficult to pass were termed as fail.

\subsubsection{4. pH Study [52-55]}

One $\mathrm{ml}$ of the prepared insitu gels was diluted with distilled water. A Digital pH meter (Shambhavi Impex, India) which was previously calibrated was used for determination of $\mathrm{pH}$ of the resulting solution.

\subsubsection{Spreadability [56]}

Spreadability was determined by placing excess of sample insitu gel between two glass slides and for 5 min under tension by placing $1000 \mathrm{~g}$ weight, the slides were compressed to uniform thickness. Spreadability is the time in seconds for two slides to slip off from insitu gel which was placed in between the slides. The slides are under the influence of certain load. The spreadability is expressed in $\mathrm{g} \mathrm{cm} \mathrm{sec}^{-1}$ (gram centimetre/seconds). 


\subsubsection{Gel Strength $[57,58]$}

Gel strength was determined by using texture analyser (Model - TA.XT2 Plus, Size- 650mm tall, 540mm deep, $280 \mathrm{~mm}$ wide, Speed - 0.01- 40mm/sec, Maximum aperture $-370 \mathrm{~mm}$, Sample testing area- $247 \mathrm{~mm}$ x $228 \mathrm{~mm}$, load cell capacity $-3 \mathrm{~g}-10 \mathrm{~kg}$, Operating temperature- $0-40^{\circ} \mathrm{C}$ ). The experiment was done by placing insitu gel in standard beaker below probe. In this, an analytical probe was depressed into the sample. The texture analyser was set to gelling strength test mode or compression mode with test speed of $1.0 \mathrm{~mm} / \mathrm{sec}$, an acquisition rate of 50 points per sec and trigger force of $3-5 \mathrm{~g}$ were selected. An aluminium probe of $7.6 \mathrm{~cm}$ diameter was used for all the prepared formulations. The study was carried out at room temperature and the force required to penetrate the gel was measured as gel strength in grams.

\subsubsection{Viscosity Studies [59, 60]}

Viscosity of insitu gel system was determined using Brook field viscometer DV-1 prime and Pro couple with S-94 spindle. Temperature of $37 \pm 0.5^{\circ} \mathrm{C}$ was maintained and the spindle was lowered perpendicularly into both insitu sol and gel formulations which were placed in a beaker. The viscosity of each formulation was determined by applying $100 \mathrm{rpm}$ speed.

\subsubsection{Rheological Studies [61-65]}

The measurement of viscosity of prepared insitu gel was done with Brookfield viscometer. The insitu formulations were rotated for 2 minutes at different speeds for selected spindle. At each speed the corresponding dial reading was noted. The viscosity of different insitu gel formulations was measured at different speeds at room temperature. A typical run should be carried out by changing the speed from 10-100 rpm (revolutions per minute).

\subsubsection{Drug Content Estimation [66, 67]}

Suitable dilutions of drug in PBS was made by dissolving $1 \mathrm{ml}$ of formulation in $10 \mathrm{ml}$ PBS of pH 6.6 which was taken in $10 \mathrm{ml}$ volumetric flask. The drug content was estimated on UV visible spectrophotometer at 309nm using PBS pH 6.6 as blank.

\subsection{In vitro Mucoadhesion Studies}

\subsubsection{In vitro Mucoadhesion Time [68, 69]}

Invitro mucoadhesion studies were performed to evaluate the mucoadhesion properties of insitu gel loaded with lamotrigine. The time required for the detachment of insitu gel spread on the nasal mucosa was determined. The tissues were kept in PBS and stored in freezer and the same was kept at room temperature before doing the test. Sections of nasal mucosa were fixed onto a glass beaker with mucosal surface facing outwards. A small quantity of nasal insitu formulation was placed on the mucosal surface previously treated with simulated nasal fluid. Mucosa fixed on to the glass beaker was then placed in the beaker containing $100 \mathrm{ml}$ of PBS and was magnetically stirred at $10 \mathrm{rpm}$. The time required for erosion of insitu gel was noted visually and considered as the invitro mucoadhesion time.

\subsubsection{In vitro Mucoadhesive Strength [70-82]}

The force used to detach the insitu gel placed in between the two nasal mucosae was determined with the help of a specialised chemical balance. The nasal mucosa mainly the bovine mucosa is used for the study. On one side of the balance the nasal mucosa is tied on a clear glass surface with help of a rubber band and another mucosa was placed in such a way that the mucosa is in inverted position to that of the first, so that both the mucosal surfaces face each other. A small quantity of the prepared insitu gel about 50mg is placed in between the two mucosae and allowed to remain in contact with each other for few minutes. For each measurement using different formulation, different mucosa was used. On the other side of the pan, weight was increased until the two mucosae were detached from each other. Mucoadhesive strength is expressed as force or stress detachment per cm square of area of mucosa used.

It is given by the equation dynes $/ \mathrm{cm}^{2}=\mathrm{mg} / \mathrm{A}$;

Where $\mathrm{m}=$ Weight in grams required for the detachment of two mucosae.

$\mathrm{g}=$ acceleration due to gravity.

$\mathrm{A}=$ Area of mucosa exposed. 


\subsection{In vitro Release Studies [83-85]}

Invitro drug release study was performed by static dissolution method. In vitro drug release was carried out by placing the prepared insitu gel formulations in a beaker containing the $50 \mathrm{ml}$ of PBS pH6.6. The temperature was maintained at $37 \pm 0.5^{\circ} \mathrm{C}$ throughout the study. Gel form was initially prepared by treating the in situ formulation with simulated nasal fluid (composition include sodium chloride $-0.745 \mathrm{gm}$, potassium chloride $-0.12 \mathrm{gm}$, calcium chloride dehydrated- $0.005 \mathrm{mg}$ distilled water $-100 \mathrm{ml}$ )which was then placed in the beaker containing PBS. Then beaker was placed on magnetic stirrer and stirred for adequate period of time. Aliquots of samples were withdrawn at regular intervals and the dissolution medium was replaced with fresh PBS. The samples withdrawn were suitably diluted with PBS pH6.6 and the amount of drug released was analysed spectrophotometrically at 309nm against PBS pH 6.6 as blank. After the in vitro release studies, the formulation with maximum release was found and the kinetic studies were done by subjecting the release data of the optimised formulation to different kinetic models and calculated the corresponding regression coefficient values $\left(\mathrm{R}^{2}\right)$.

\subsection{Ex vivo Permeation Study [86-93]}

Franz diffusion cell was used for doing the exvivo permeation study. The diffusion cell has receptor compartment of $15 \mathrm{ml}$ capacity which was filled with PBS of pH6.6. Bovine nasal mucosal tissue used in ex vivo permeation was obtained from local slaughter house and cut in suitable shape. Bovine mucosa was selected since it resembles human nasal mucosa. Mucosal tissue was properly placed over the receptor compartment. From $20 \mathrm{mg}$ containing $10 \mathrm{ml}$ of optimised formulation $1 \mathrm{ml}$ of in situ gel formulation was placed in the donor compartment. Aliquots of samples were withdrawn from the receptor compartment at regulator intervals and fresh samples were replaced into receptor compartments. Samples were suitably diluted and drug content was analysed spectrophotometrically at $309 \mathrm{~nm}$. The permeation study was done for optimised G5 insitu formulation and control containing drug in PBS pH 6.6 and comparison was done among them for steady state flux value for a maximum period of $12 \mathrm{~h}$. Statistical analysis of the data was carried out by performing Students T Test.

\subsection{Histopathological Study [94-96]}

The pre-treated mucosa after in vitro permeation was subjected to histopathological examinations for knowing any changes after accepted procedure. Nasal mucosa treated with control and optimised G5formulation were subjected to histopathological examination using a light microscope. 10\% buffered formalin ( $\mathrm{pH} 7.0$ ) used to fix tissue was routinely processed and embedded in paraffin. Sections $(5 \mu \mathrm{m})$ were cut on glass slides and stained with hematoxylin and eosin.

\subsection{Scanning Electron Microscopy (SEM) [97]}

The optimised insitu G5 formulation was suitably diluted and examined with SEM.

\subsection{Transmission Electron Microscopy (TEM) [98]}

The optimised insitu G5 formulation was subjected to TEM, in which a beam of electrons was transmitted through the sample to form an image.

\subsection{Stability Studies [99, 100]}

The optimised insitu gel formulation (G5) underwent stability evaluation for 45 days in refrigerated $\left(4 \pm 2^{\circ} \mathrm{C}\right)$, room temperature $\left(30 \pm 2^{\circ} \mathrm{C}\right)$ and oven $\left(40 \pm 2^{\circ} \mathrm{C}\right)$ conditions and analysed for drug content and gel strength at regular intervals. Mean values were recorded.

\section{RESULTS AND DISCUSSION}

\subsection{Preformulation Studies}

\subsubsection{FTIR Spectroscopy}

FTIR of pure drug lamotrigine in Fig. (1) was found to be in accordance with monograph (IP). 


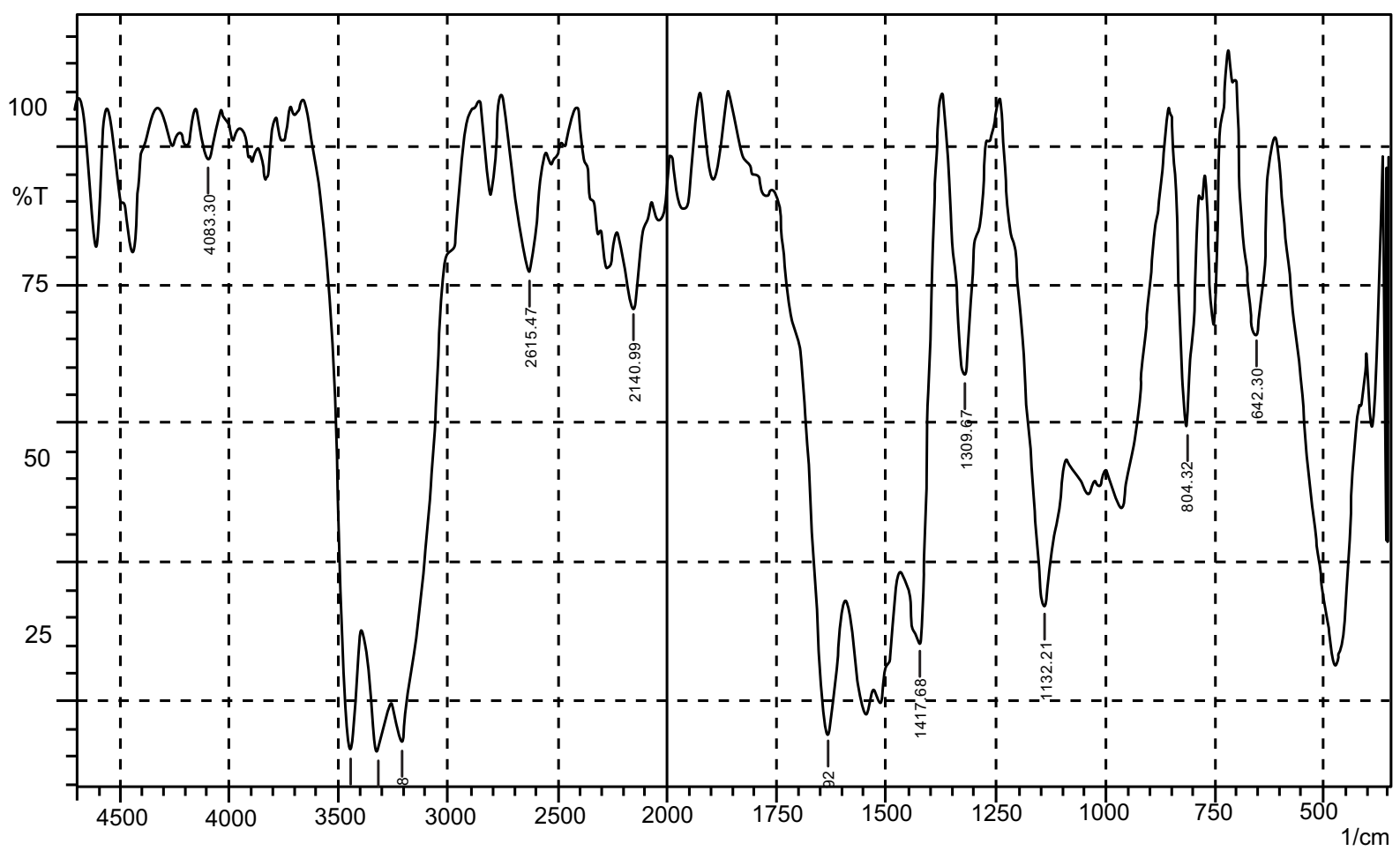

Fig. (1). FTIR spectrum of sample lamotrigine.

\subsubsection{Solubility Studies}

The pure drug is partially soluble in water and ethanol and completely soluble in methanol, acetone, PBS pH 6.6.

\subsubsection{Melting Point}

The melting point of the drug was found to be $225-235^{\circ} \mathrm{C}$ and it was in accordance with that of the reference.

\subsubsection{Partition Coefficient}

Partition coefficient of the drug was found to be 1.1 indicating that the drug is practically insoluble in water and has high lipophlilicity.

\subsubsection{Lambda max of Lamotrigine in Methanol}

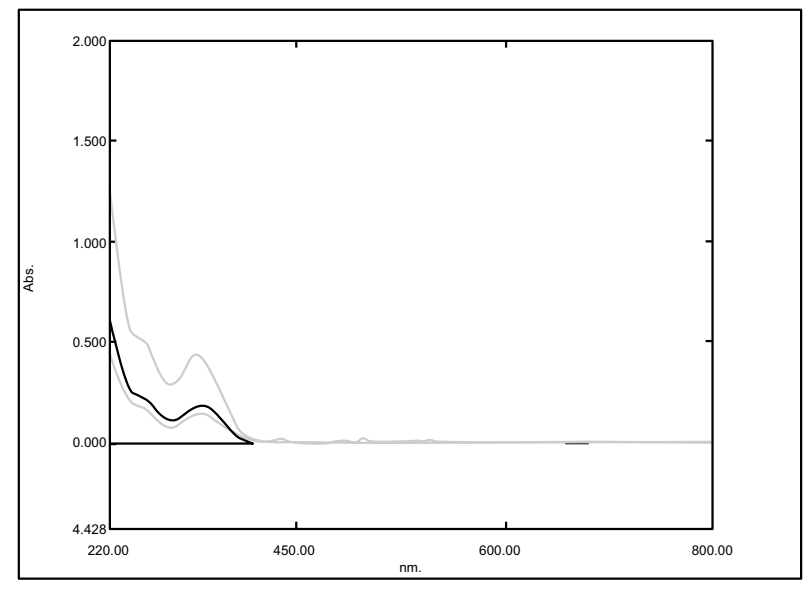

a

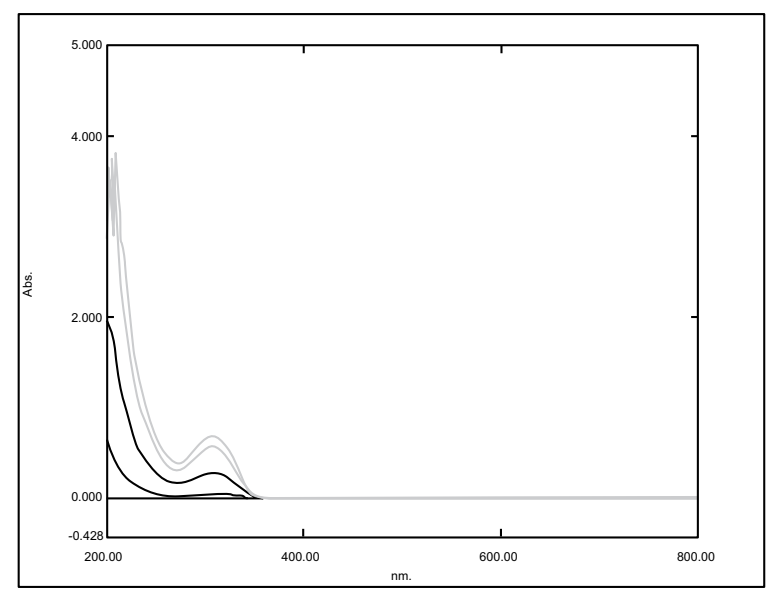

b

Fig. (2). a) Absorption maxima of lamotrigine in methanol; and b) Absorption maxima of lamotrigine in $\mathrm{PBS}$ pH 6.6 . 
The absorption maxima of lamotrigine in methanol was found to be $309 \mathrm{~nm}$ as shown in Fig. (2a), which was in accordance with the official standard.

\subsubsection{Lambda Max of Lamotrigine in PBS pH6.6}

The absorption maxima of lamotrigine in PBS pH 6.6 was found to be $309 \mathrm{~nm}$ (Fig. 2b).

\subsubsection{Compatibility Studies of the Drug Lamotrigine with the Excipients}

FTIR spectra of lamotrigine, gellan gum, xanthan gum, drug with gellan gum, drug with xanthan gum, insitu gel formulation are shown in (Fig. 3).

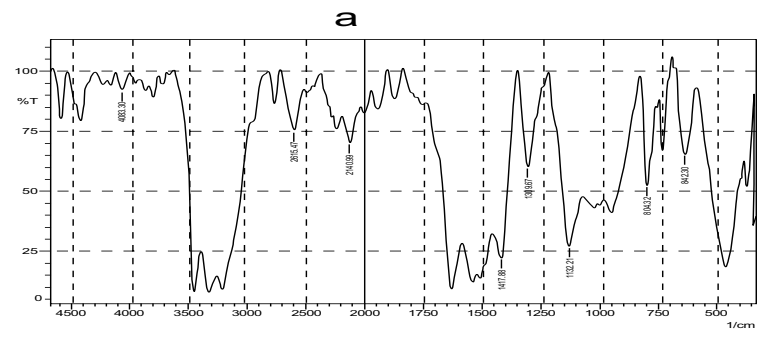

C

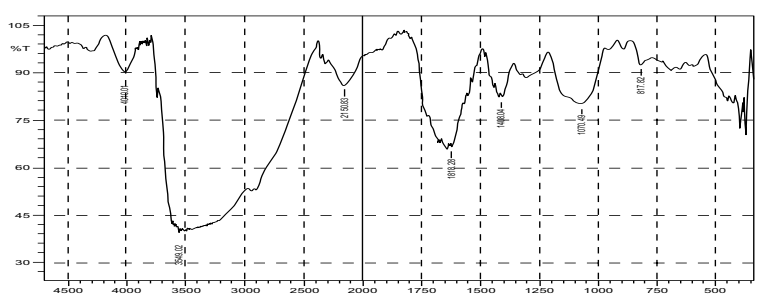

$\mathbf{e}$

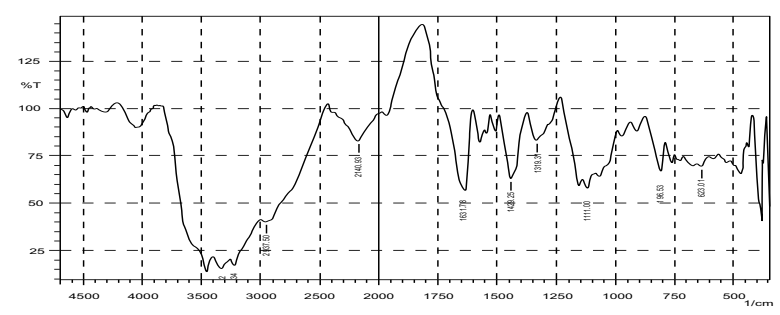

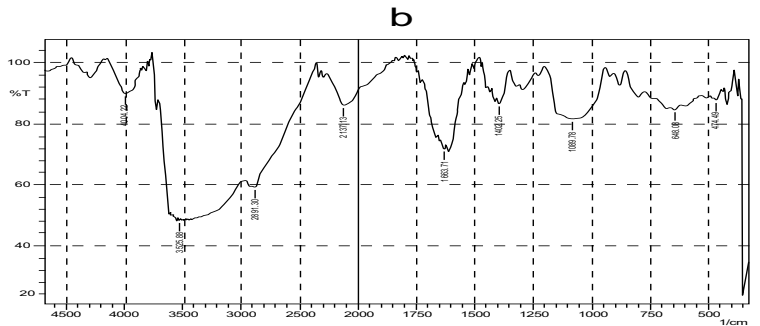

d

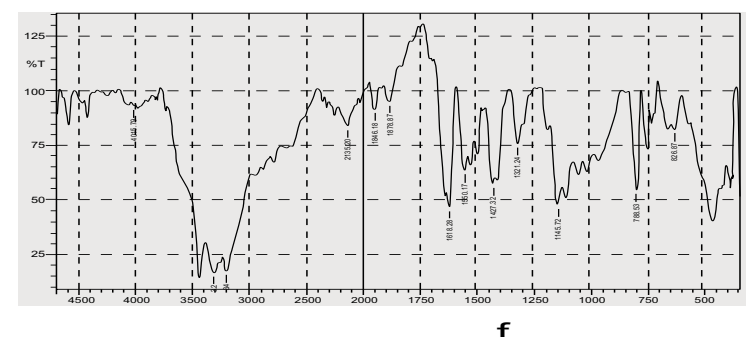

$f$

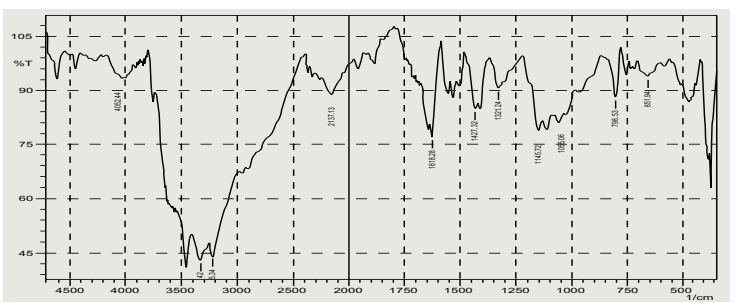

Fig. (3). FTIR spectra of a) lamotrigine; b) gellan gum; c) xanthan gum; d) drug with gellan gum; e) drug with xanthan gum; and f) in situ gel formulation.

- FTIR spectra of Lamotrigine shown in Fig. (3a) showed characteristic absorbance at $3446 \mathrm{~cm}^{-1}$ specifying NH stretching of amino group, $3211 \mathrm{~cm}^{-1}$ shows aromaticity (aromatic $\mathrm{CH}$ stretching), $1627 \mathrm{~cm}^{-1}, 1417 \mathrm{~cm}$ indicates $\mathrm{C}=\mathrm{C}$ ring stretching, and $843.02 \mathrm{~cm}^{-1}$ shows $\mathrm{C}-\mathrm{Cl}$ stretching of halides .

- FTIR spectra of gellan gum shown in Fig. (3b) showed a broad strong peak at $3525 \mathrm{~cm}^{-1}$ indicating the presence of $\mathrm{OH}$ group, and $2891 \mathrm{~cm}^{-1}$ shows aromatic $\mathrm{CH}$ stretching.

- FTIR spectra of Xanthan gum shown in Fig. (3c) also showed a broad peak at $3549 \mathrm{~cm}^{-1}$ which also relieved the presence of $\mathrm{OH}$ group.

- FTIR spectra of insitu gel formulation exhibited a sharp peak at $3315 \mathrm{~cm}^{-1}$ which unveiled the existence of amino group (NH stretching of NH group), $325.34 \mathrm{~cm}^{-1}$ indicates aromatic $\mathrm{CH}$ stretching, $1627 \mathrm{~cm}^{-1}, 1427 \mathrm{~cm}^{-1}$ shows $\mathrm{C}=\mathrm{C}$ ring stretching, 798-659 $\mathrm{cm}^{-1}$ displays $\mathrm{C}-\mathrm{Cl}$ stretching of Halides, and a strong absorbance peak at 3445 reveals the presence of $\mathrm{OH}$ group.

- Absence of extra peaks indicates good compatibility between drug and excipients.

\subsubsection{XRD Studies}

The XRD pattern of both insitu formulation and lamotrigine is shown in Figs. (4a and $\mathbf{4 b})$, respectively. The 
characteristic XRD patterns demonstrate the crystalline nature of lamotrigine. XRD pattern of lamotrigine has sharp and intense peak appearing at 12.1, 13.2, 24.9, 27.52 theta values. While comparing the XRD pattern of drug with the insitu formulation, the latter showed a decrease in the intensity and number of peak. This clearly indicates the degree of amorphous nature of formulation. The crystalline nature of lamotrigine was reduced in the insitu formulation.

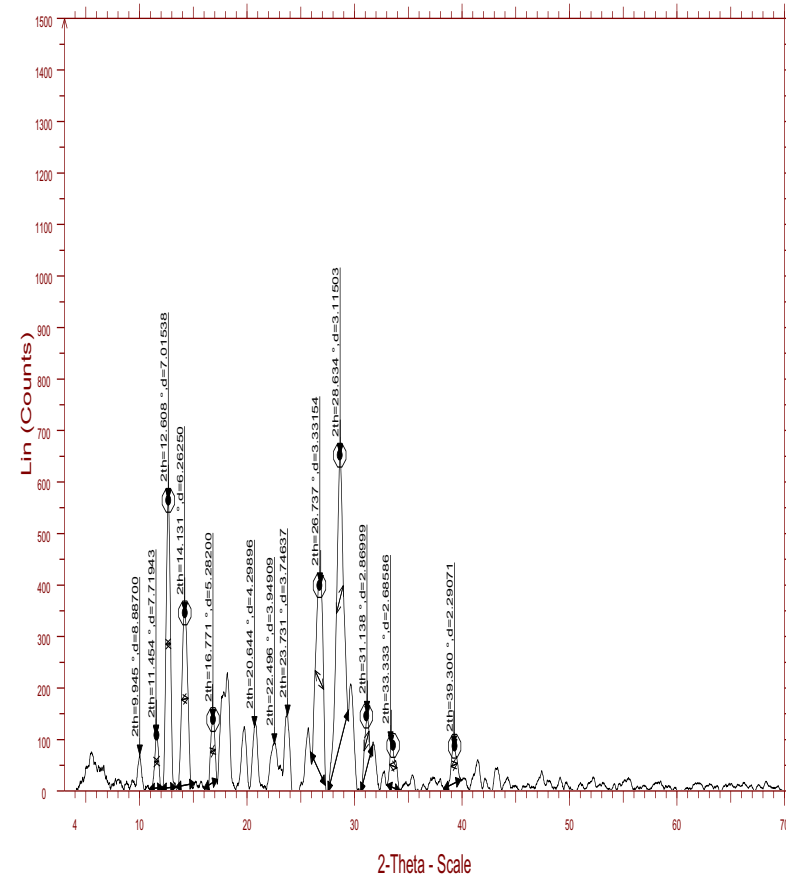

a

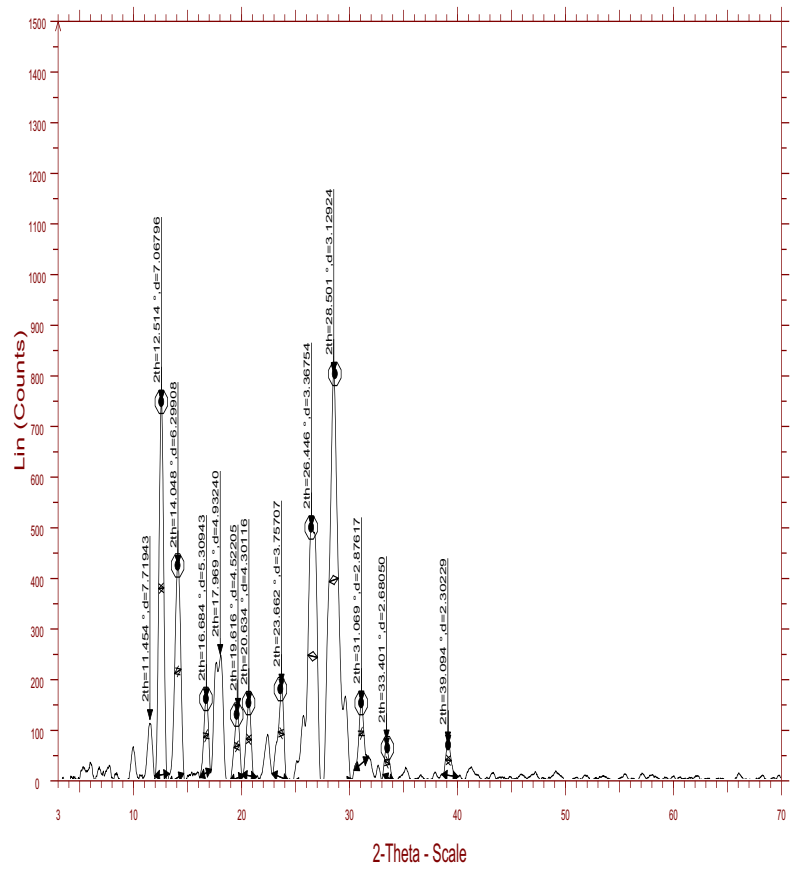

b

Fig. (4). a) XRD pattern of insitu formulation; and b) XRD pattern of drug lamotrigine.

\subsection{Analytical Methods}

\subsubsection{Calibration Curve of Lamotrigine in Methanol}

The calibration curve of lamotrigine in methanol was found to be linear in concentration range of 5-30 $\mu \mathrm{g} / \mathrm{ml}$. The calibration curves are shown in (Fig. 5a).

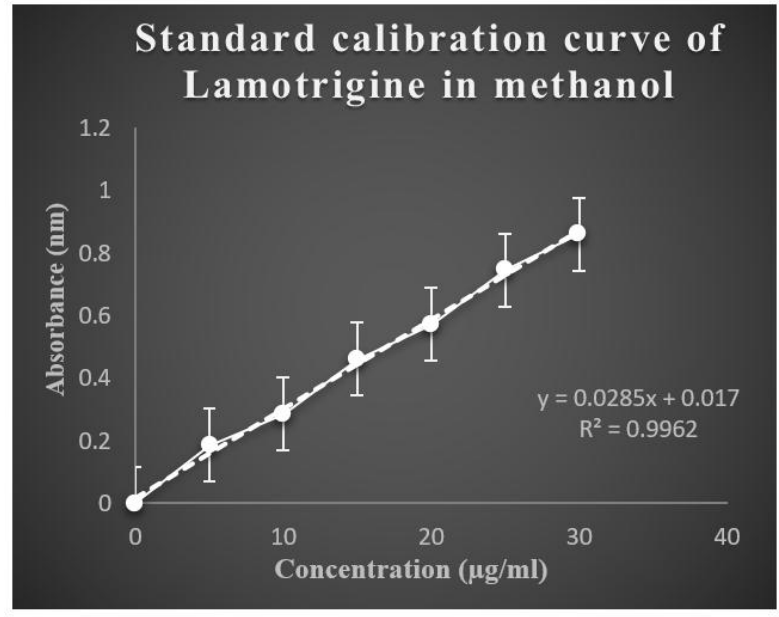

a

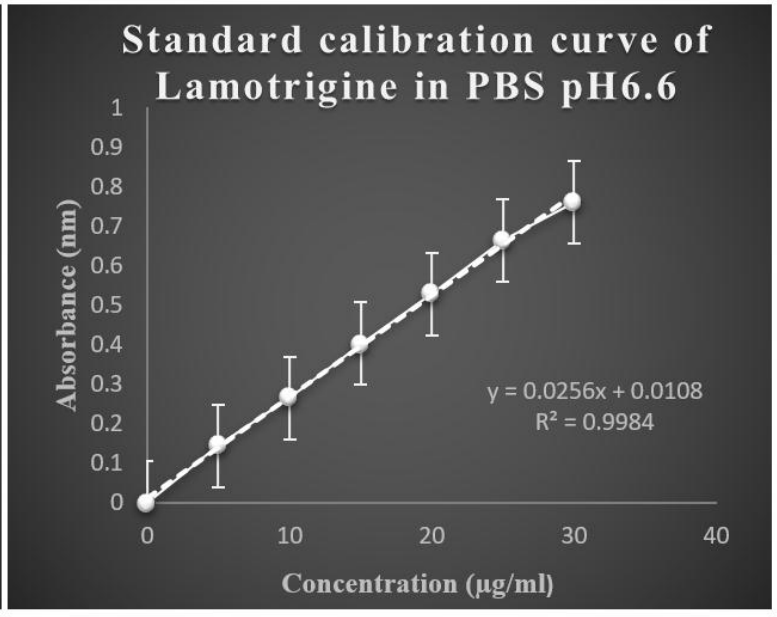

b

Fig. (5). a) Standard calibration curve of lamotrigine in methanol, b)Standard calibration curve of lamotrigine in phosphate buffer $\mathrm{pH}$ 6.6 . 


\subsubsection{Calibration Curve of Lamotrigine in PBS pH 6.6}

The calibration curve of lamotrigine in phosphate buffer pH6.6 was found to be linear in concentration range of $5-30 \mu \mathrm{g} / \mathrm{ml}$. The calibration curves are shown in (Fig. 5b).

\subsection{Characterisation}

\subsubsection{Homogeneity Studies}

All the prepared in situ gels showed noble homogeneity with the absence of lumps indicating uniform drug distribution of the formulation.

\subsubsection{Gelling Time}

The gelling time of the formulation ranged between $3.4 \pm 0.21 \mathrm{sec}$ and $11.3 \pm 0.22 \mathrm{sec}$. The formulations G5 showed an adequate gelling time. Gelling time of all formulations is mentioned in Table $\mathbf{2}$ and Fig. 6 a.

Table 2. Gelling time, Syringeability, pH, Spreadability, Gel strength, and Viscosity of different insitu gel formulations.

\begin{tabular}{|c|c|c|c|c|c|c|c|}
\hline Formulations & Gelling time (sec) & Syringeability & $\mathbf{p H}$ & Spreadability (gcm/sec)* & Gel Strength (g) & \multicolumn{2}{c|}{ Viscosity (cps) } \\
\hline - & - & - & - & - & - & sol & gel \\
\hline G1 & $11.3 \pm 0.21$ & Pass & $5.8 \pm 0.01$ & $15.24 \pm 0.72$ & $3.1 \pm 0.56$ & $19 \pm 0.27$ & $93 \pm 0.52$ \\
\hline G2 & $10.2 \pm 0.34$ & Pass & $5.9 \pm 0.02$ & $21.30 \pm 1.19$ & $4.7 \pm 0.74$ & $27 \pm 0.35$ & $107.4 \pm 0.45$ \\
\hline G3 & $9.5 \pm 0.41$ & Pass & $6.1 \pm 0.02$ & $25.15 \pm 1.24$ & $5.9 \pm 0.81$ & $34 \pm 0.25$ & $122.2 \pm 0.11$ \\
\hline G4 & $7.2 \pm 0.35$ & Pass & $6.3 \pm 0.04$ & $29.76 \pm 1.36$ & $6.5 \pm 0.63$ & $40.16 \pm 0.36$ & $146.13 \pm 0.63$ \\
\hline G5 & $5.2 \pm 0.61$ & Pass & $6.5 \pm 0.02$ & $34.33 \pm 1.42$ & $6.9 \pm 0.94$ & $46.83 \pm 0.33$ & $168 \pm 0.85$ \\
\hline G6 & $4.6 \pm 0.41$ & Fail & $6.6 \pm 0.08$ & $42.71 \pm 1.51$ & $7.2 \pm 0.72$ & $58.16 \pm 0.74$ & $180 \pm 0.25$ \\
\hline G7 & $3.4 \pm 0.52$ & Fail & $6.8 \pm 0.05$ & $56.19 \pm 1.66$ & $7.7 \pm 1.25$ & $80.26 \pm 0.53$ & $218 \pm 0.63$ \\
\hline
\end{tabular}

(Values are expressed as mean \pm standard deviation, $n=3$

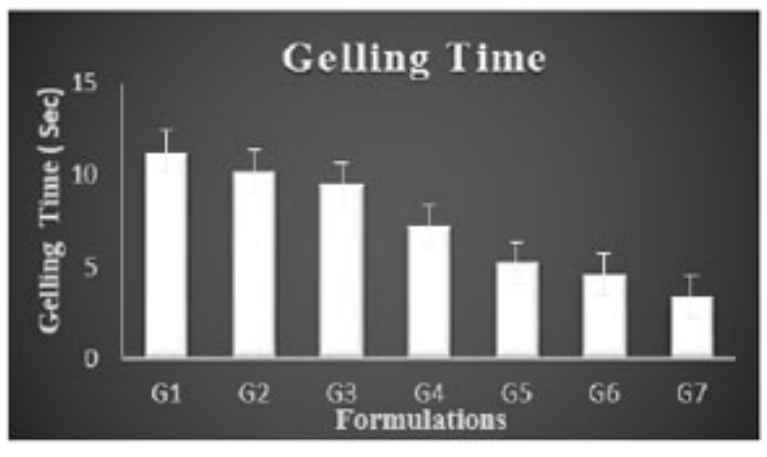

a

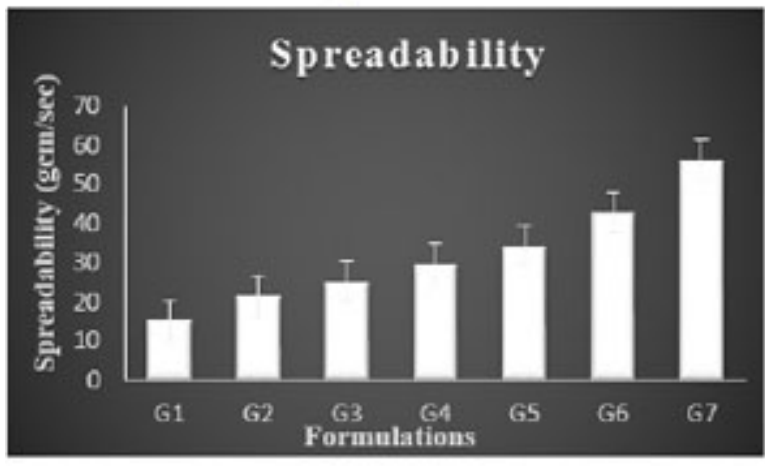

c

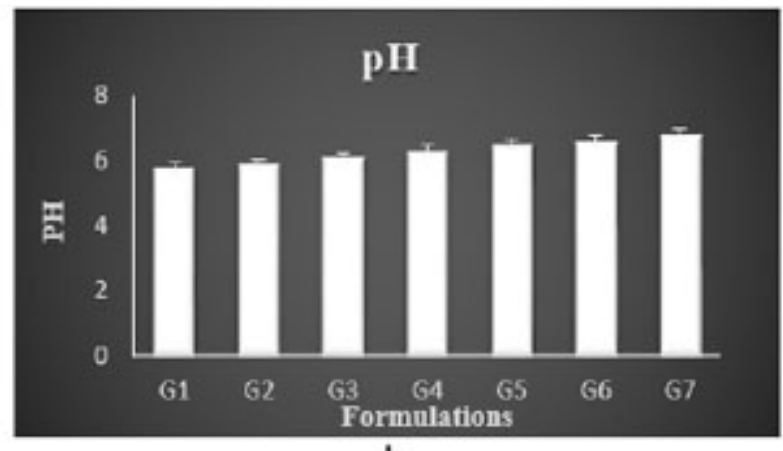

b

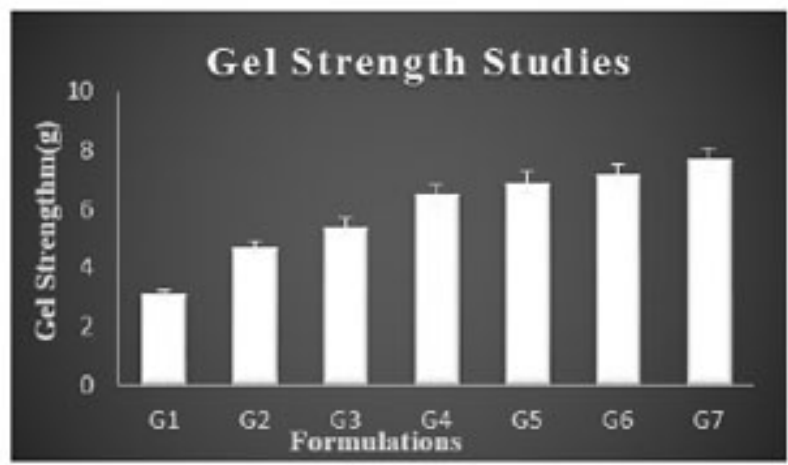

d

Fig. (6). a) Showing gelling time; b) pH; c) Spreadability; d) Gel strength of different formulations of insitu gel of lamotrigine. 


\subsubsection{Syringeablity}

All the formulations from G1- G5 passed syringeability test and showed good syringeability except G6 and G7as shown in Table (2). Syringeablity test was conducted for ensuring that the prepared formulation was having proper solution flow nature so that the formulation can be used to deliver the insitu sol to the target site. The syringeability depends on 3 parameters mainly viscosity of the system, flow rate, and needle characteristics. Syringeablity mainly depends on the concentration of the polymer and viscosity. Since the former ones especially G5 and G4 were having lesser polymer concentration which exhibited good Syringeablity. As the polymer concentration was increased the syringeability was reduced.

\subsection{4. $\mathrm{pH}$}

$\mathrm{pH}$ value of all insitu gel formulation ranged in between 5.8-6.4, indicating that the formulation was suitable and better for nasal administration with reduced irritation of tissue. $\mathrm{pH}$ of all the formulations is given in Table $\mathbf{2}$ and Fig. $(\mathbf{6 b})$.

\subsubsection{Spreadability Studies}

The formulated insitu gel exhibited satisfactory spreadability indicating easy application of drug. The spreadability of the optimised insitu formulation was in the range of $34.33 \pm 1.42 \mathrm{~g} \mathrm{~cm} /$ second. Spreadability studies were shown in Fig. (6c and Table 2.

\subsubsection{Gel Strength}

Gel strength of different insitu gel formulation was in the range of $3.1 \pm 0.56 \mathrm{~g}$ and $7.7 \pm 0.45 \mathrm{~g}$ as given in Fig. (6d) and Table 2.

\subsubsection{Viscosity Studies}

One important pre-requisite for intranasal in situ gel was viscosity of the formulation. As indicated, a formulation suitable for application to the nasal cavity should ideally have a low viscosity when applied and after administration should have a high viscosity in order to stay at the application site. All the formulations of batches G1-G7 showed a polymer concentration dependent rise in viscosity. Viscosity of the both insitu sol and insitu gel was examined at 100rpm. G7 formulation was having maximum viscosity. The viscosity of G5 formulation was taken as optimum. Viscosity of insitu sol formulation ranged between $19 \pm 0.27-80.26 \pm 0.53 \mathrm{cps}$. Viscosity of insitu gel ranged between $93 \pm 0.52$ to $218 \pm 0.63 \mathrm{cps}$ as shown in Fig. 7a and Table (2).

\subsubsection{Rheological Studies}

This is an important parameter for the in situ gels to be evaluated. This study excluded G6 and G7 formulations since these formulations do not have sufficient syringeability and such formulations are avoided because of difficulty in administration. The viscosity of formulations should be in an optimum range which improves its ease of administration. The flow curve (viscosity against speed / rpm) of selected formulations indicated that for the selected polymer concentrations, pseudoplastic systems with shear thinning property were obtained. The prepared formulations tend to thin when being exposed to shearing force. Fig. (7b) compares the shear dependent viscosity of prepared formulations containing gellan gum and xanthan gum.

\subsubsection{Drug content Estimation}

The drug content was estimated for all prepared in situ gel formulation. Acceptable range of drug content in the range of $86.12 \pm 0.32 \%-97.6 \pm 0.68 \%$ was present in all of them indicating uniform distribution of drug. The maximum amount of drug was present in G5 formulation with $97.6 \pm 0.68 \%$. The concentration of drug content proportionally depends on polymer concentration, But when polymer concentration is too high the concentration of drug was slightly less when compared to the former ones. The drug concentration was estimated to be maximum when $1.75 \% \mathrm{w} / \mathrm{v}$ of polymer was used. Drug content estimation was given in Table $\mathbf{3}$. 
Table 3. Drug content, Mucoadhesion time, and Mucoadhesive strength of different in situ gel formulations.

\begin{tabular}{|c|c|c|c|}
\hline Formulations & $\begin{array}{c}\text { Drug } \\
\text { Content (\%) }\end{array}$ & Mucoadhesive Time (min) & Mucoadhesive Strength (dynes $/ \mathrm{cm}^{2}$ ) \\
\hline G1 & $89.89 \pm 1.52$ & $120 \mathrm{~min}$ & $2046 \pm 0.56$ \\
\hline G2 & $92.16 \pm 0.34$ & $151 \mathrm{~min}$ & $2393 \pm 0.42$ \\
\hline G3 & $94.35 \pm 0.41$ & $184 \mathrm{~min}$ & $2628 \pm 0.61$ \\
\hline G4 & $96.10 \pm 0.85$ & $216 \mathrm{~min}$ & $2853 \pm 0.75$ \\
\hline G5 & $97.61 \pm 0.68$ & $254 \mathrm{~min}$ & $3018 \pm 0.67$ \\
\hline G6 & $93.75 \pm 0.96$ & $318 \mathrm{~min}$ & $3295 \pm 0.72$ \\
\hline G7 & $86.12 \pm 0.32$ & $364 \mathrm{~min}$ & $3526 \pm 0.56$ \\
\hline
\end{tabular}

(Values are expressed as mean \pm standard deviation, $\mathrm{n}=3$ )

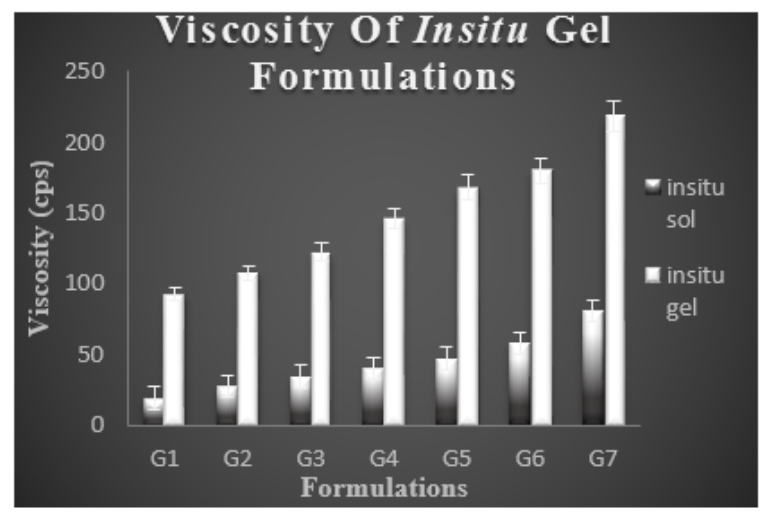

a

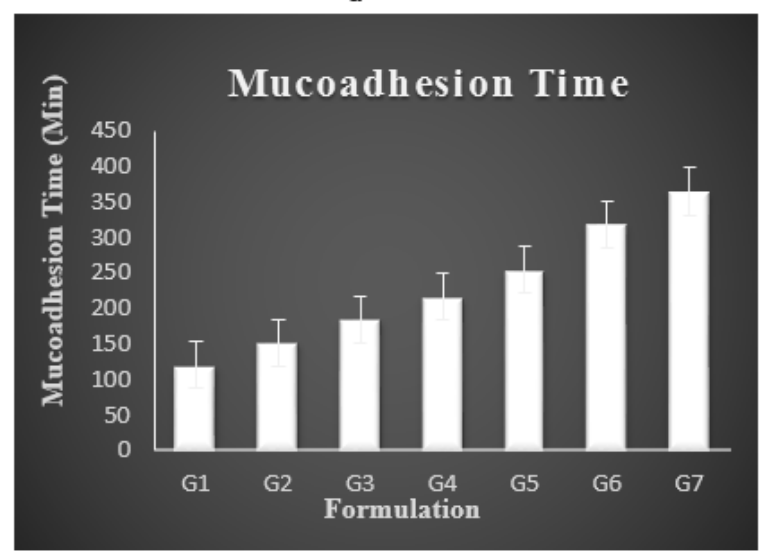

c

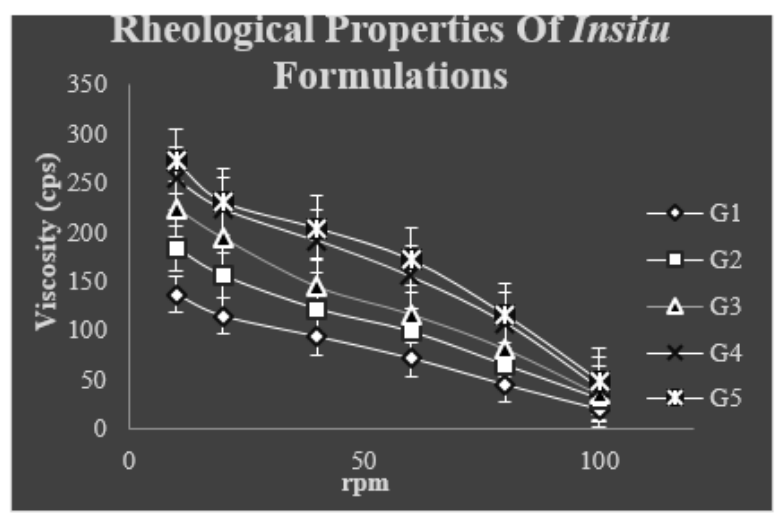

b

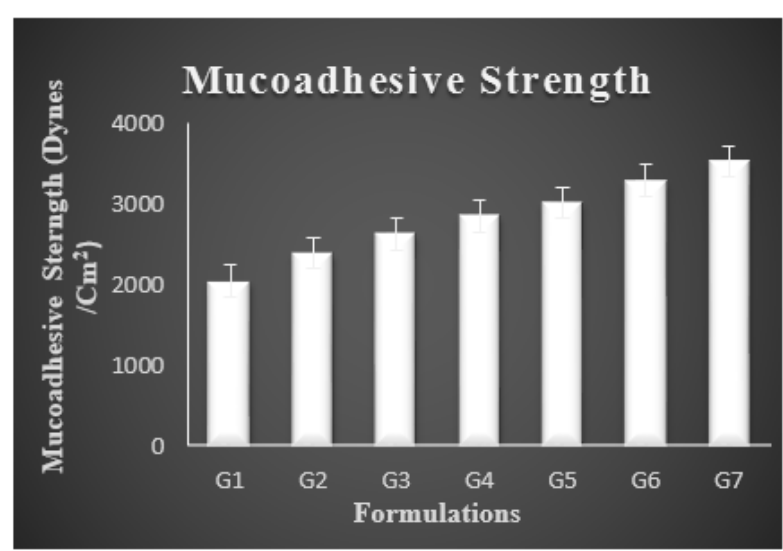

d

Fig. (7). a) Viscosity; b)Rheological properties; c) Mucoadhesion time; d) Mucoadhesive strength of different formulations of in situ gel of lamotrigine.

\subsection{In vitro Mucoadhesion Studies}

\subsubsection{In vitro Mucoadhesion Time}

Mucoadhesion time taken for the insitu gel to erode from the nasal mucosa was noted. The adhesion time taken for G5 formulation was found to be higher than other formulation. Mucoadhesion is imparted by the formulation due to the addition of a natural mucoadhesive polymer gellan gum. Bioadhesive time was found to be increasing with raising concentration of gellan gum. Higher mucoadhesive time of optimised formulation indicates that it can be attached to the nasal mucosa for longer period with less risk of mucocilliary clearance and provides a sustained effect. Mucoadhesive time of all the formulations is mentioned in Table 3 and Fig. (7c). 


\section{Mucoadhesion can be explained by two stages:}

- The spreading and swelling of formulation when the mucoadhesive polymer binds to mucous membrane mark the first stage, i.e contact stage.

- The next stage is the activation of mucoadhesive polymer, which is due to the interaction of mucoadhesive polymer with the ions present on the nasal mucosa.

\subsubsection{In vitro Mucoadhesive Strength}

Mucoadhesion studies were carried out to ensure that the formulation had the ability to adhere to the mucous membrane at the site of absorption for a long period of time. With increase in polymer concentration a raise in mucoadhesion was seen. The mucoadhesive character is exhibited by the polymer gellan gum, by interaction of the specific functional groups in polymer like hydroxyl and carboxyl group with the glycoprotein chain in the mucous layers of epithelial cells of nasal cavity. The interactions can be strong or weak like wander walls interaction, ionic bonding and hydrogen bonding. The polymer is an ion activated one which upon interaction with the physiological ions in the nasal electrolytes form gel. The interaction of the polymer with the glycoprotein chains in the mucin network occurs when the polymer swells by absorbing water from the mucous layer and adhesion binding occurs to form gel. The key factors that play a major role in mucoadhesion are the physiological ions in the nasal cavity as well as the swelling capacity of the polymer which finally result in prolonged mucoadhesion and reduced mucocilliary clearance. Mucoadhesive strength of all the formulations is mentioned in Fig. (7d) and Table 3.

\subsection{In vitro Release Studies}

The in vitro release studies of different formulations of drug loaded in situ gels were carried out for 20minute in PBS pH6.6. PBS of pH6.6 was selected as medium for drug absorbance since it resembles nasal pH. Throughout the study the $\mathrm{pH}$ and temperature were kept constant. The maximum release was found to be for G5 and G4 with respective release of $97.02 \pm 0.54 \%$ and $95.96 \pm 0.16 \%$. The polymer concentration plays a key role in release pattern of drug. The release of drug mainly depends on the polymer concentration. Polymer concentration was proportional to release to some extent. But too high concentration of the polymer can adversely affect the in vitro release as in formulation G7. The G5 formulation was showing highest percentage release and was regarded as the optimised formulation. The drug: wax ratio was optimum for the G5 formulation which was the reason for its immediate release. Fig. (8) shows the $i n$ vitro release of different in situ gel formulations.

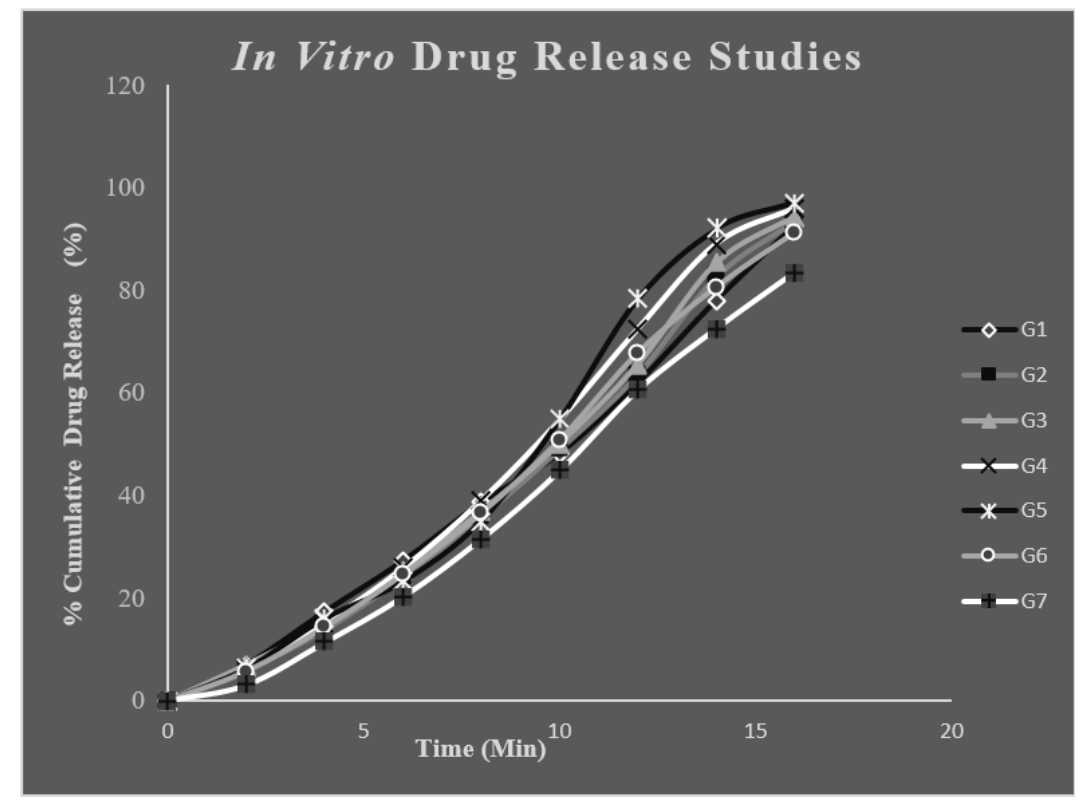

Fig. (8). In vitro drug release studies of different in situ formulation. 


\subsection{Kinetics}

The G5 formulation was having the maximum drug release. Based on the in vitro drug release data kinetic study was done for optimised G5 formulation. The drug release mechanism was investigated by subjecting the release data of the optimised formulation to different kinetics models. On comparing the regression coefficient values of different kinetic models, it was observed that the $\mathrm{R}^{2}$ value of different kinetic models and release data were found to be $1^{\text {st }}$ order which was best fitted with Korsmeyer peppas model where the $\mathrm{n}$ value was greater than 0.5 , indicating non fickan transport mechanism of drug release. Fig. (9) shows the different kinetic models of optimised insitu gel G5 formulation

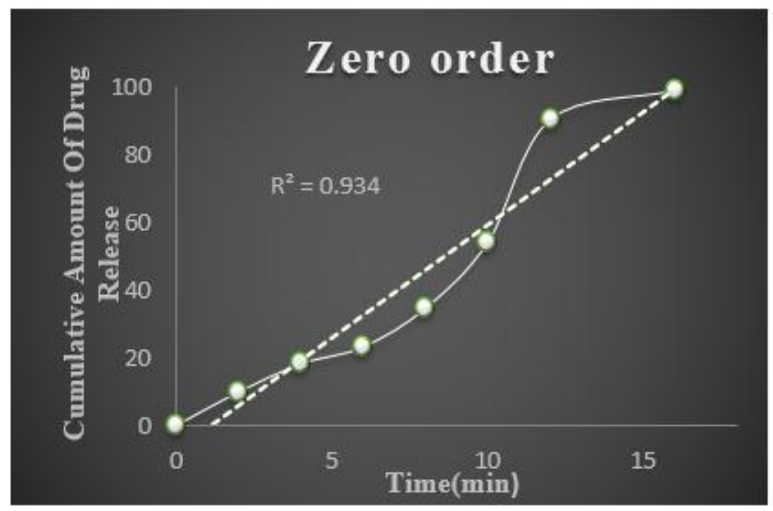

a

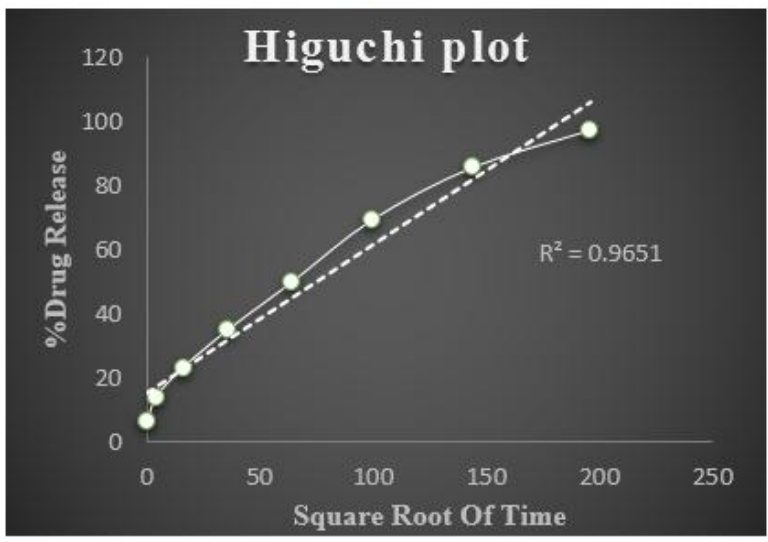

c

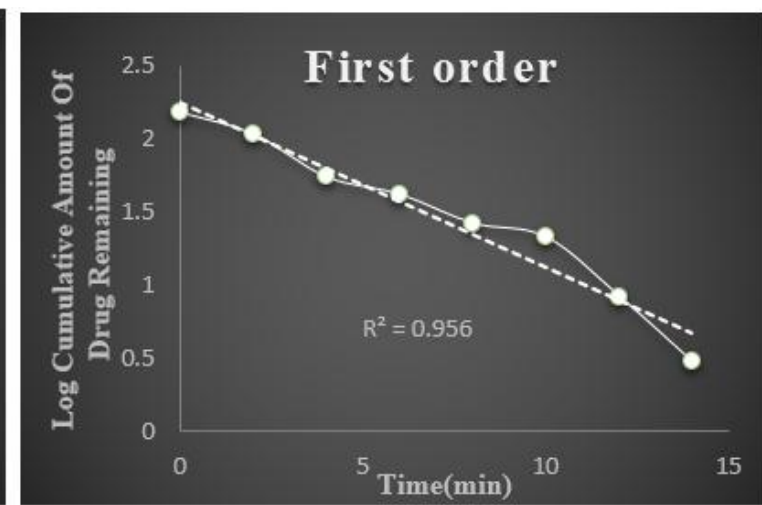

b

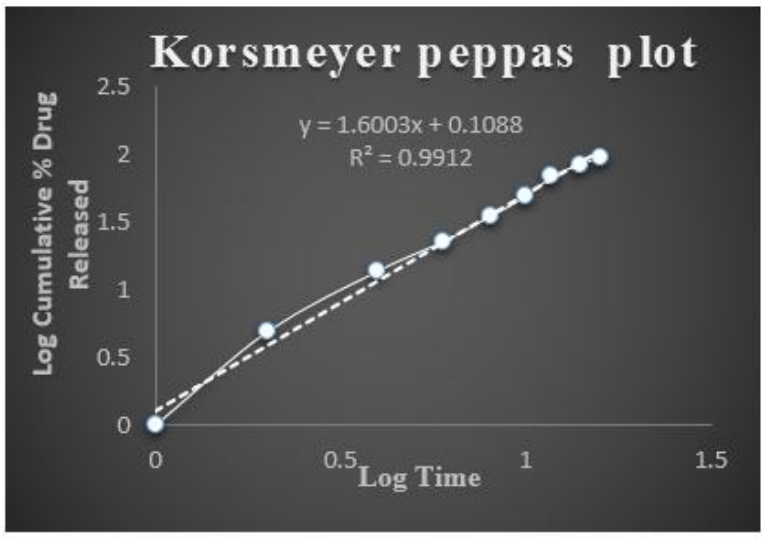

d

Fig. (9). (a) Zero order kinetics; (b) first order kinetics; (c) Higuchi plot; (d) Korsmeyer peppas model.

\subsection{Ex vivo Permeation Studies}

Franz diffusion cell was used for conducting exvivo permeation studies. The permeation studies were conducted by using bovine nasal mucosa for 12 hours. The bovine nasal mucosa was selected because of its physiological resemblance to human nasal mucosa. The nasal mucosa represents a layer with higher vascularisation. The exvivo permeation study was done for optimised G5 formulation and control formulation containing the drug in PBS pH6.6 and comparison studies done between them were plotted on a graph. G5 optimised formulation was showing maximum permeation than control indicating slow and sustained permeation of drug from nasal mucosa. The release process of the drug from the preparation depends on the dissolution from the gel in aqueous media and more viscous gels release lamotrigine more slowly than less viscous solutions. These results indicate that the viscosity of the insitu gel plays an important role in controlling the release of the drug if the dissolution of the drug through the polymer matrix is a rate determining step. The exvivo permeation studies of the above mentioned two formulations are given in (Fig. 10). 


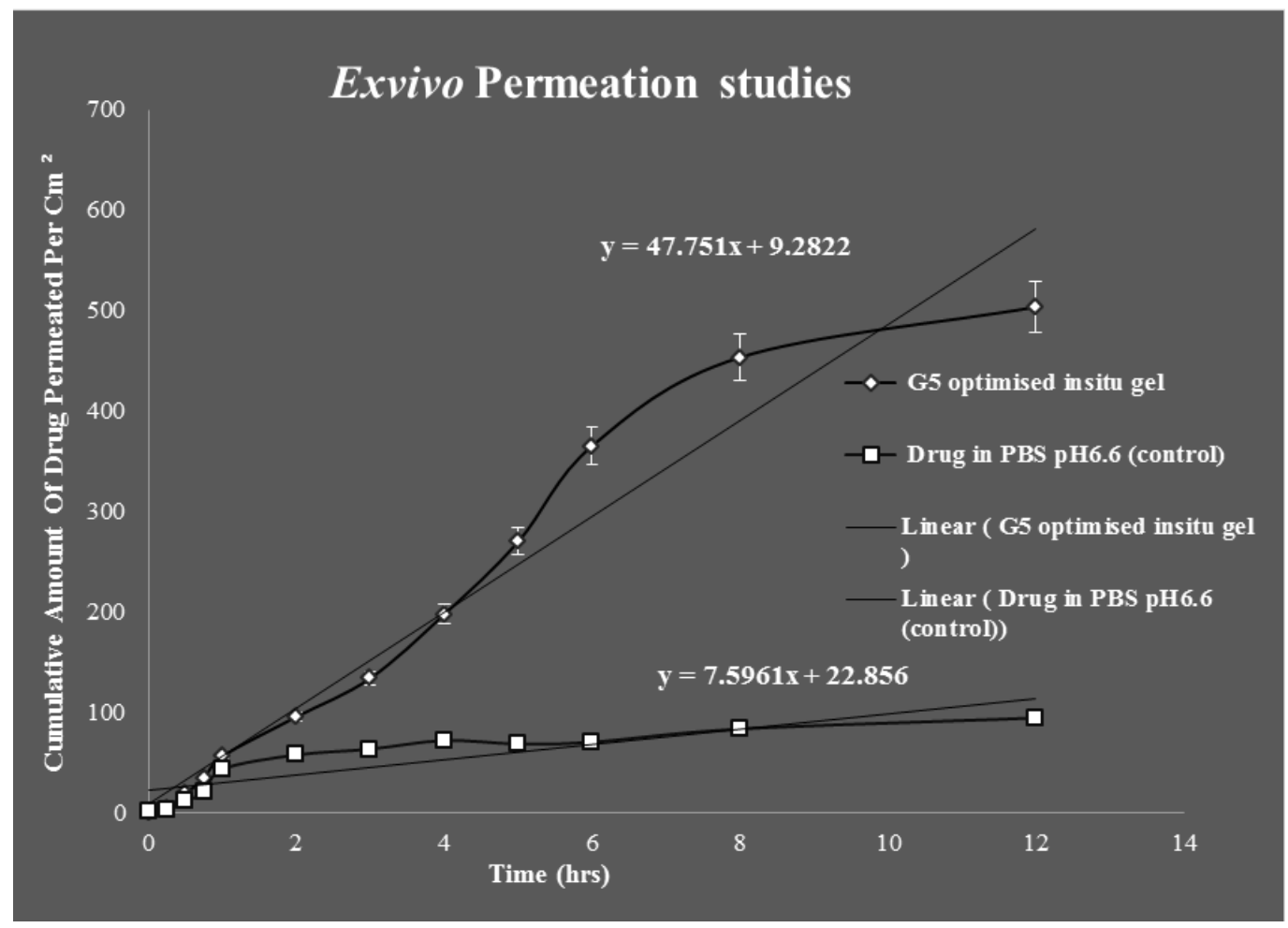

Fig. (10). Ex vivo permeation studies of G5 insitu optimised gel and control formulations.

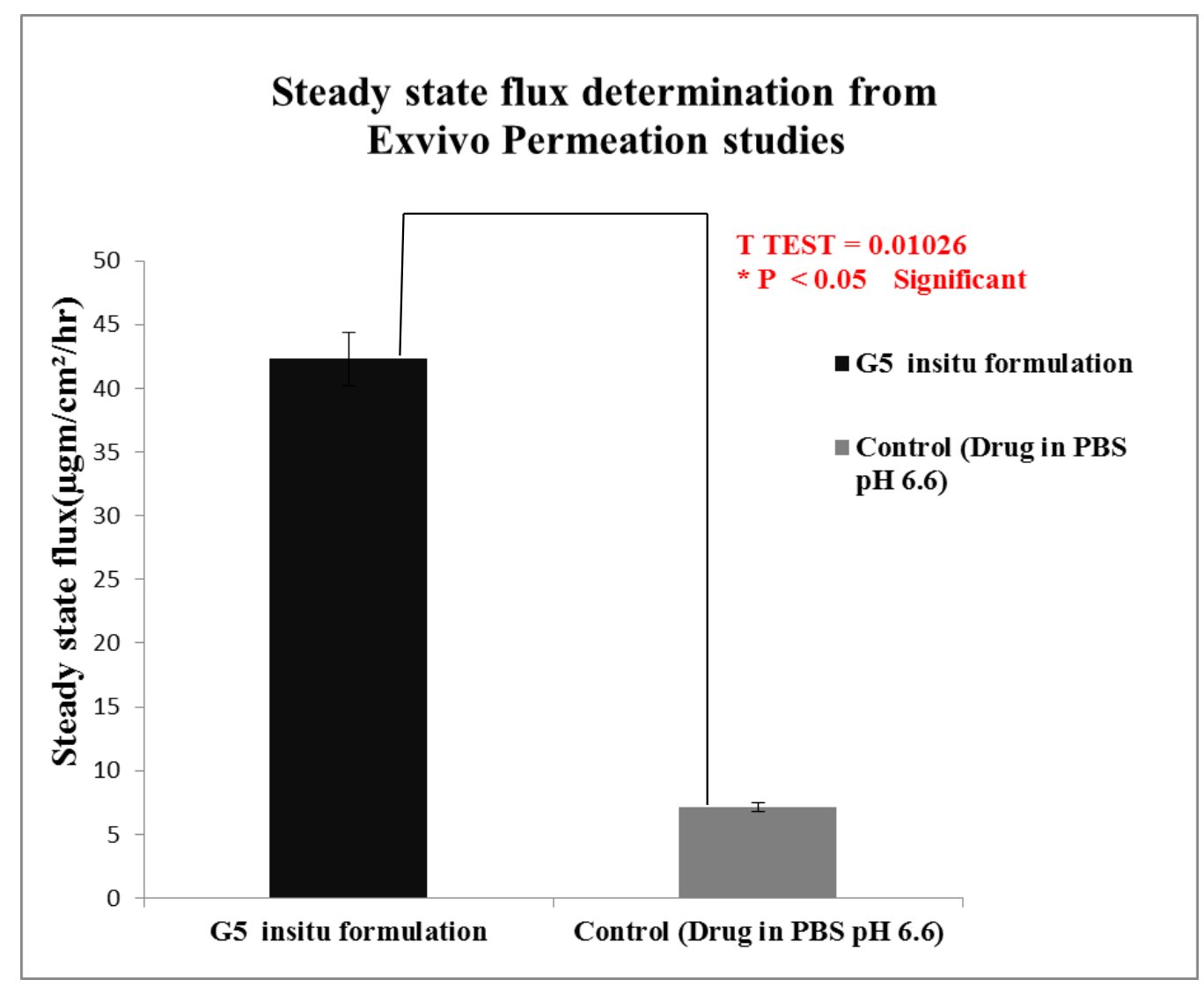

Fig. (11). Steady state Flux determination from exvivo permeation studies of optimised G5 formulation and positive control. 
Students T Test were carried out for statistical analysis of data and the P value was 0.0126 which was significant, since $\mathrm{p}$ value is $<0$ 05. Statistical analysis showed significant improvement in the exvivo permeation of the optimised G5 insitu formulation than when compared to control.

Ex vivo studies revealed that amount of lamotrigine permeated per $\mathrm{cm}^{2}$ was improved significantly $(\mathrm{P}<0.05)$ for $\mathrm{G} 5$ formulation than when compared to positive control.

The permeability coefficient and steady state flux values of the G5 insitu optimised formulation were higher than the positive control. Fig. (11) shows comparison of steady state flux between the optimised insitu G5 formulation and control containing drug in PBS at $\mathrm{pH}$ 6.6.

\subsection{Histopathological Examination}

Fig. (12a and 12b) shows the histopathological study of nasal mucosa after permeation with optimised G5 formulation which does not cause any irritation or toxicity and was safe for nasal administration.

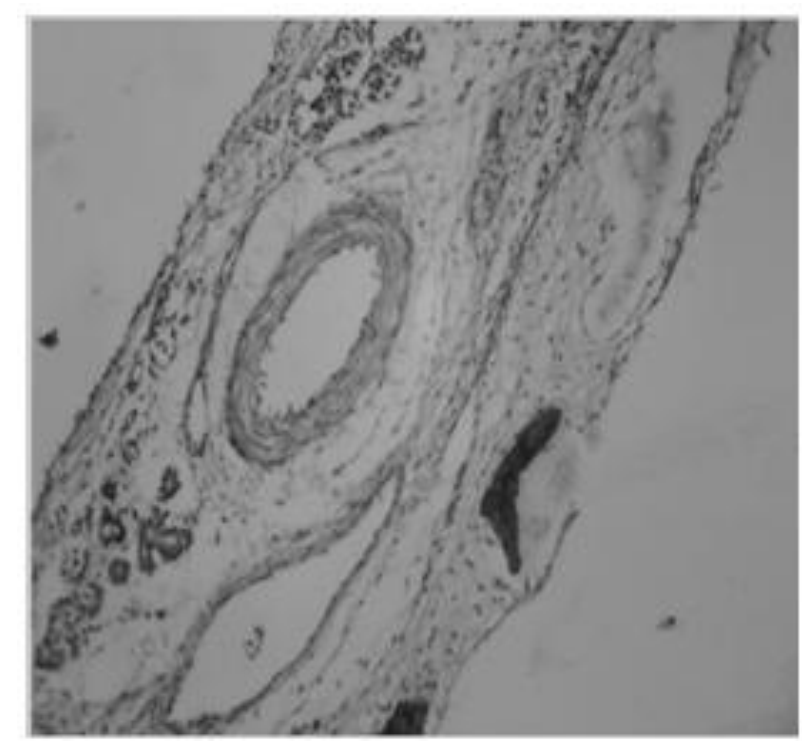

a

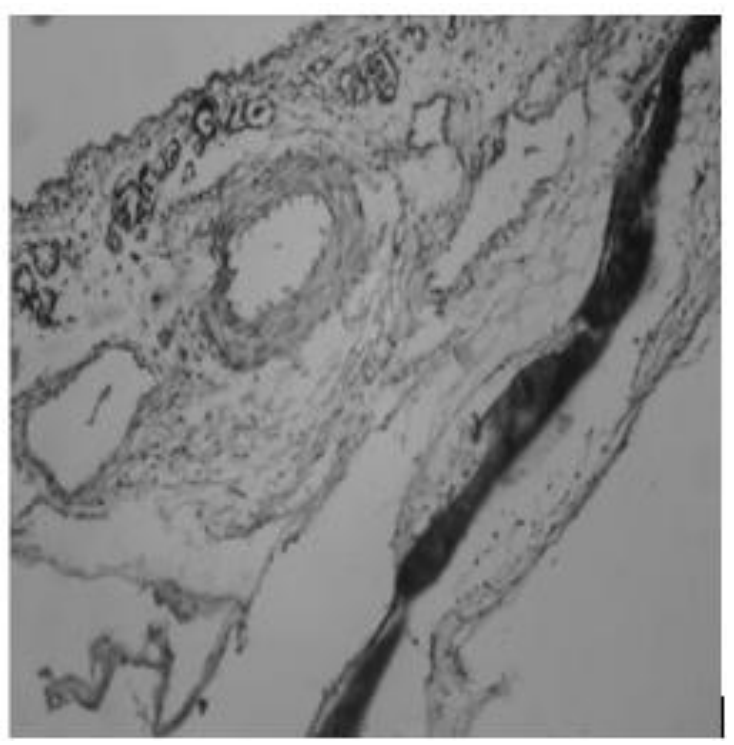

b

Fig. (12). Histopathological evaluation of nasal mucosa. a) Normal mucosa; b) Mucosa treated with optimised formulation.

\subsection{SEM}

SEM studies Fig. (13a) show discrete, spherical shaped with a rough outer surface. Visible wrinkles are shown in the SEM studies.

\subsection{TEM}

The shape and morphology of the insitu gel formulation can be studied by TEM image. TEM image of the lamotrigine loaded insitu gel formulation is shown in Fig. (13b), indicating spherical particles in nanometre range which are homogeneously distributed throughout the formulation.

\subsection{Stability Studies}

Parameters like drug content and gel strength were evaluated from 0 day to 45 days at regular intervals in 3 different conditions i.e, refrigerated, room temperature and oven conditions. The optimised G5 insitu gel formulation was found to be more stable at refrigerated and room temperature conditions than in oven condition. Table 4 and Fig. (14a) a show the drug content and Table 4 and Fig. (14b) show gel strength of optimised in situ G5 formulation during stability studies over a period of 45 days. 


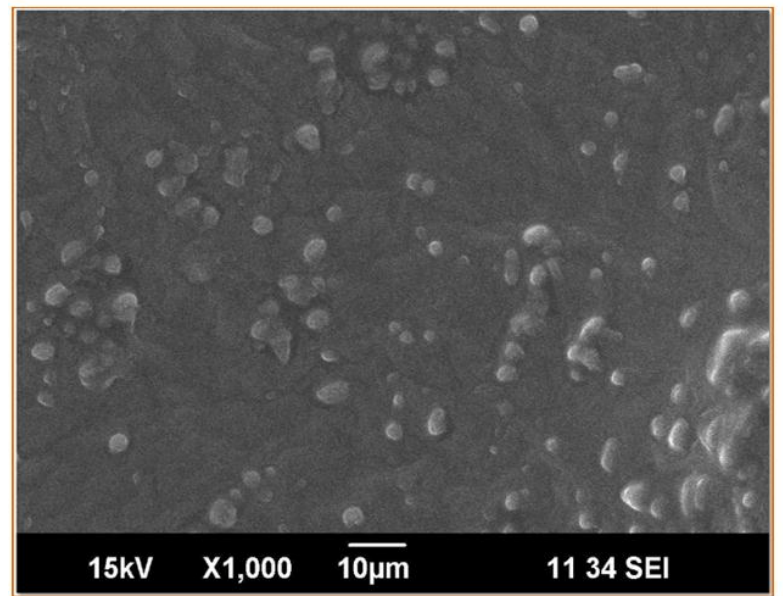

a

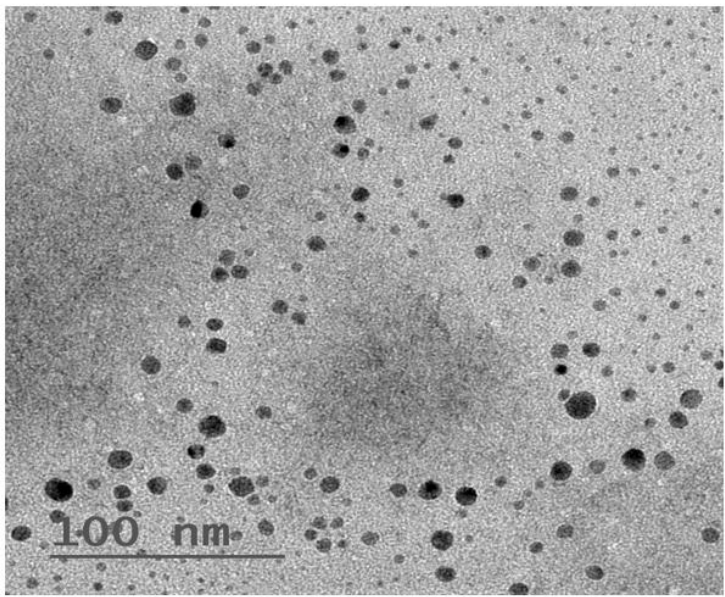

b

Fig. (13). a) SEM image of lamotrigine loaded insitu gel formulation; b) TEM image of Lamotrigine loaded insitu gel formulation.

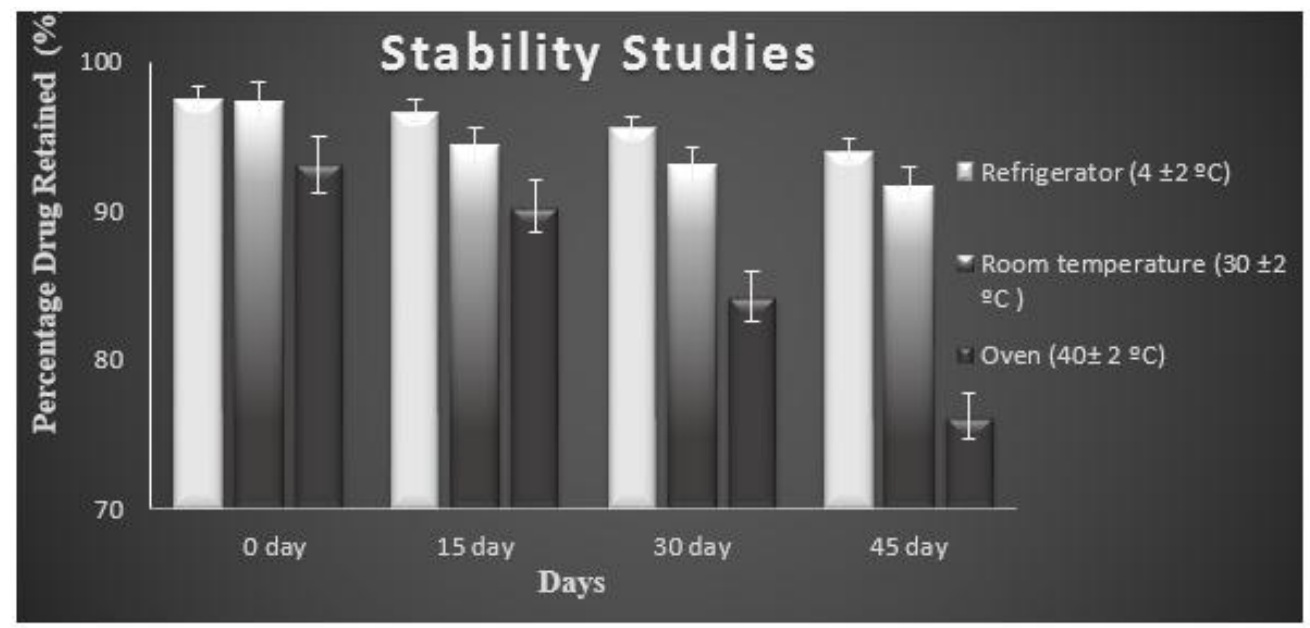

a

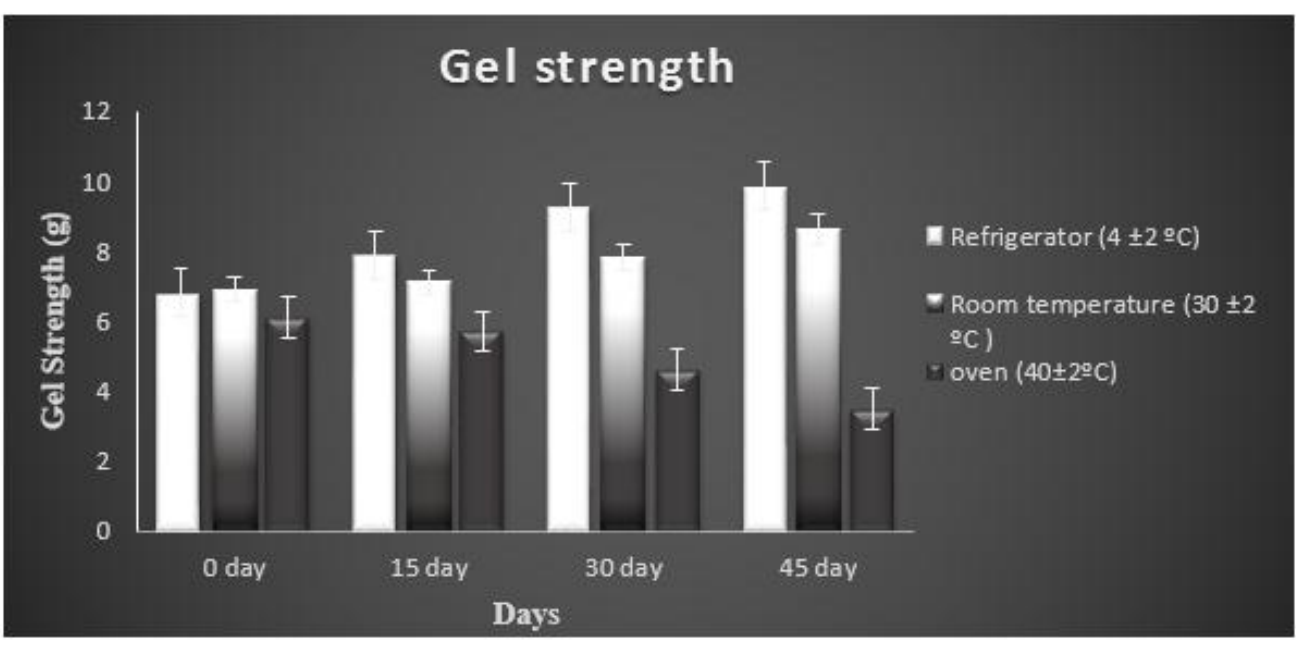

b

Fig. (14). a) Drug content; b) Gel strength of optimised insitu gel G5 formulation during stability studies at different conditions. 
Table 4. Stability studies of optimised G5 insitu gel formulation.

\begin{tabular}{|c|c|c|c|c|c|c|c|c|}
\hline \multirow{2}{*}{$\begin{array}{c}\text { Temperature } \\
-\end{array}$} & \multicolumn{4}{|c|}{ Drug Content } & \multicolumn{4}{|c|}{ Gel Strength(g) } \\
\hline & O day & 15 day & 30 day & 45 day & 0 day & 15 day & 30 day & 45 day \\
\hline $\begin{array}{c}\text { Refrigerator } \\
\left(4 \pm 2^{\circ} \mathrm{C}\right)\end{array}$ & $97.2 \pm 0.48$ & $97.7 \pm 0.62$ & $96.6 \pm 0.64$ & $95.1 \pm 0.51$ & $6.8 \pm 0.64$ & $7.9 \pm 0.91$ & $9.25 \pm 1.94$ & $9.86 \pm 2.41$ \\
\hline Room temperature $\left(30 \pm 2^{\circ} \mathrm{C}\right)$ & $97.9 \pm 0.23$ & $97.4 \pm 0.56$ & $96.1 \pm 0.52$ & $94.3 \pm 0.46$ & $6.9 \pm 0.41$ & $7.1 \pm 0.94$ & $7.8 \pm 1.34$ & $8.6 \pm 1.64$ \\
\hline Oven $\left.40 \pm 2^{\circ} \mathrm{C}\right)$ & $96.1 \pm 0.33$ & $90.3 \pm 0.35$ & $84.3 \pm 0.51$ & $76.2 \pm 0.54$ & $6.1 \pm 0.53$ & $5.7 \pm 1.25$ & $4.6 \pm 2.19$ & $3.5 \pm 2.45$ \\
\hline
\end{tabular}

(Values are expressed as mean \pm standard deviation, $\mathrm{n}=3$ )

\section{CONCLUSION}

Epilepsy is a common chronic neurological disorder characterized by recurrent epileptic seizures. A number of delivery systems have been investigated but still a novel delivery system to combat this incurable firing disorder is yet to be developed. Intranasal drug delivery is one of the local drug delivery routes to combat this neurological disorder due to high vascularisation, larger surface area and porous endothelial membrane providing systemic effect and avoidance of first pass metabolism. It is also a non-invasive route. Antiepileptic drugs commonly used in treating epilepsy especially in conventional treatments are probably associated with many side effects. The main purpose of this study was to formulate an insitu gel drug delivery system with immediate release for treating epileptic condition that can minimize first pass metabolism and side effects by loading lamotrigine into different concentration of natural biodegradable polymeric solutions of gellan gum and xanthan gum that increases the mucoadhesion and residence time, reducing the mucocillary clearance and are also responsible for gelling property of the formulation. Among all the formulation G5 was fixed to be the optimised formulation, which had maximum drug release of $97.02 \pm 0.54 \%$ and greater permeation significantly $(p<0.05)$ than control. Histopathological studies showed there is no alteration in drug treated nasal mucosa after permeation with optimised formulation when compared with normal nasal mucosa, this indicates less irritation to the nasal mucosa. Administration of drug loaded insitu gel formulation into nasal cavity proves to be viable and effective alternative to other conventional therapy and in future its clinical use is promising.

\section{ETHICS APPROVAL AND CONSENT TO PARTICIPATE}

Not applicable.

\section{HUMAN AND ANIMAL RIGHTS}

No Animals/Humans were used for studies that are base of this research.

\section{CONSENT FOR PUBLICATION}

Not applicable.

\section{CONFLICT OF INTEREST}

The authors declare no conflict of interest, financial or otherwise.

\section{ACKNOWLEDGEMENTS}

Declared none.

\section{REFERENCES}

[1] Wallace, H.; Shorvon, S.; Tallis, R. Age-specific incidence and prevalence rates of treated epilepsy in an unselected population of 2,052,922 and age-specific fertility rates of women with epilepsy. Lancet, 1998, 352(9145), 1970-1973. [http://dx.doi.org/10.1016/S0140-6736(98)04512-7] [PMID: 9872246]

[2] More, B.A.; Mene, H.R.; Pawar, R.K.; Misal, N.S.; Pathak, S.S.; Shivsharan, K.J. A Review on insitu Nasal Gel Drug Delivery system. Int. J. Pharm. Sci. Rev. Res., 2015, 33(1), 199-207.

[3] Vinayan, K.P.; Solomon, L.M. Neonatal seizures and epilepsies. Int. J. Epilepsy., 2014, 1, 75-83. [http://dx.doi.org/10.1016/j.ijep.2014.08.001]

[4] Chaundhar, SP.; Chaundhar, PP.; Kolsure, PK.; Barhate, NS.; Despande, AD. Preformulation study of sumatriptain succinate nasal gel. Ind. Drugs, 2006, 43, 966-971. 
[5] Nirmal, H.B.; Bakliwal, S.R.; Pawar, S.P. Insitu gel -New trend in controlled and sustained drug delivery system. Int. J. Pharm. Tech. Res., 2010, 2, 1398-1408.

[6] Mathison, S.; Nagilla, R.; Kompella, U.B. Nasal route for direct delivery of solutes to the central nervous system: Fact or fiction? J. Drug Target., 1998, 5(6), 415-441.

[http://dx.doi.org/10.3109/10611869808997870] [PMID: 9783675]

[7] Schipper, N.G.; Verhoef, J.C.; Merkus, F.W. The nasal mucociliary clearance: relevance to nasal drug delivery. Pharm. Res., 1991, 8(7), 807-814. [http://dx.doi.org/10.1023/A:1015830907632] [PMID: 1924131]

[8] Illum, L. Transport of drugs from the nasal cavity to the central nervous system. Eur. J. Pharm. Sci., 2000, 11(1), 1-18. [http://dx.doi.org/10.1016/S0928-0987(00)00087-7] [PMID: 10913748]

[9] Watts, P.; Smith, A. PecSys: In situ gelling system for optimised nasal drug delivery. Expert Opin. Drug Deliv., 2009, 6(5), 543-552. [http://dx.doi.org/10.1517/17425240902939135] [PMID: 19413461]

[10] Czapiński, P.; Blaszczyk, B.; Czuczwar, S.J. Mechanisms of action of antiepileptic drugs. Curr. Top. Med. Chem., 2005, 5(1), 3-14. [http://dx.doi.org/10.2174/1568026053386962] [PMID: 15638774]

[11] Umesh, G.H.; Kumar, H.; Mishra, G.; Sharma, A.K.; Gothwal, A.; Kesharwani, P. Intranasal drug delivery: A Noninvasive approach for the better delivery of Neurotherapeutics. Pharma. Nanotechnol., 2017, 5(4), 1-12.

[12] James, E.; Kuriakose, S.; Kumar, A. Assessment of knowledge of epilepsy in epileptic patients attending a tertiary care centre in Kerala. Int J. Pharm. Pharm. Sci., 2014, 6(7), 64-67.

[13] Ramesh, K.; Krishnapriya, M. Anupriya, Nair, SC. An outlook to nonpharmacological and novel approaches to combat the uncurable firing disorder. Int. J. Pharm. Sci. Rev. Res., 2016, 40(1), 55-61.

[14] Patil, S.B.; Sawant, K.K. Chitosan microspheres as a delivery system for nasal insufflation. Colloids Surf. B Biointerfaces, 2011, 84(2), 384-389.

[http://dx.doi.org/10.1016/j.colsurfb.2011.01.030] [PMID: 21320767]

[15] Madan, M.; Bajaj, A.; Lewis, S.; Udupa, N.; Baig, J.A. In situ forming polymeric drug delivery systems. Indian J. Pharm. Sci., 2009, 71(3), $242-251$. [http://dx.doi.org/10.4103/0250-474X.56015] [PMID: 20490289]

[16] Talegaonkar, S.; Mishra, P.R. Intranasal delivery: An approach to bypass blood brain barrier. Indian J. Pharmacol., 2004, 36(3), 140-147.

[17] Krishnapriya, M.; Ramesh, K.; Nair, S.C. Antiepileptic rectal hydrogel loaded with carbamazepine - Rice bran wax microspheres. Asian J. Pharm. Clin. Res., 2017, 10(3), 264-270.

[http://dx.doi.org/10.22159/ajpcr.2017.v10i3.16144]

[18] Appasaheb, P.S.; Manohar, S.D.; Bhanudas, S.R. A Review on intranasal drug delivery. J. Adv. Pharm. Educ. Res., 2013, 3, 334.

[19] Arora, P.; Sharma, S.; Garg, S. Permeability issues in nasal drug delivery. Drug Discov. Today, 2002, 7(18), 967-975. [http://dx.doi.org/10.1016/S1359-6446(02)02452-2] [PMID: 12546871]

[20] Chajed, S.; Sangle, S.; Barhate, S.D. Advantagious nasal drug delivery system: A review. Int. J. Pharm Sci. Res., 2011, $2(6)$, 1322-1336.

[21] Swamya, N.G.; Abbas, Z. Mucoadhesive insitu gels as nasal drug delivery systems: An overview. Asian J. Pharm. Sci., 2012, 7(3), 168-180.

[22] Kute, J.U.; Darekar, A.B.; Saudagar, R.B. Insitu gel-novel approach for nasal delivery. World J. Pharm. Pharm. Sci., 2013, 3(1), 187-203.

[23] Chaudhary, B.; Verma, S. Preparation and evaluation of novel insitu gels containing acyclovir for the treatment of oral herpes simplex virus infections. Sci. World J., 2014, 280.

[24] Wilmshurst, J.M.; Gaillard, W.D.; Vinayan, K.P.; Tsuchida, T.N.; Plouin, P.; Van Bogaert, P.; Carrizosa, J.; Elia, M.; Craiu, D.; Jovic, N.J.; Nordli, D.; Hirtz, D.; Wong, V.; Glauser, T.; Mizrahi, E.M.; Cross, J.H. Summary of recommendations for the management of infantile seizures: Task force report for the ILAE commission of pediatrics. Epilepsia, 2015, 56(8), 1185-1197. [http://dx.doi.org/10.1111/epi.13057] [PMID: 26122601]

[25] Sharma, A.; Sharma, J.; Kaur, R.; Saini, V. Development and characterization of in situ oral gel of spiramycin. Biol. Med. Res. Int., 2014. 876182

[26] Jain, S.K.; Jain, A.; Gupta, Y.; Ahirwar, M. Design and development of hydrogel beads for targeted drug delivery to the colon. AAPS Pharm. Sci. Tech., 2007, 8(3), E56. [http://dx.doi.org/10.1208/pt0803056] [PMID: 17915806]

[27] Fahim, F.; Naseer, A.; Ahmed, S.; Sherazi, S.T.; Bhanger, M.I. A green approach for the determination of selected anti diabetic drugs in pharmaceutical formulation by transmission FTIR spectroscopy. J. Braz. Chem. Soc., 2014, 25(11), 2032-2038.

[28] Nasra, M.M.; Khiri, H.M.; Hazzah, H.A.; Abdallah, O.Y. Formulation, in-vitro characterization and clinical evaluation of curcumin in-situ gel for treatment of periodontitis. Drug Deliv., 2017, 24(1), 133-142. [http://dx.doi.org/10.1080/10717544.2016.1233591] [PMID: 28156166]

[29] Swati, R.; Sandeep, W.; Swaroop, L. Insitu gel formulation of ornidazole for the treatment of periodontal disease. Curr. Pharm. Res., 2010, 1(1), 60-69. 
[30] Prasad, K.M.; Ravindranath, B.S.; Sheetal, B.G. Nasal insitu gel: A novel approach for nasal drug delivery system. World J. Pharm. Res, 2015, 4(2), 686-708.

[31] Patil, S.K.; Dhage, A.N.; Patil, S.V.; Patil, S.S. Formulation and Evaluation of nasal in situ gel for Alzheimer's disease. Int. Res. J. Pharma. Bio. Sci, 2015, 2(2), 41-58.

[32] Jouyban, A.; Soltanpour, S.; Acree, W.E. Improved prediction of drug solubilities in ethanol + water mixtures at various temperatures. Biomedicine Int, 2010, 1, 19-24.

[33] Martins, M.T.; Paim, CS; Steppe, M. LC and UV methods for lamotrigine determination in pharmaceutical formulation. Chromatogr. Res. Int., 2011, 8.

[34] Viram, P.; Lumbhani, A.N. Development and Evaluation of ion dependent insitu nasal gelling system of metoclopramide hydrochloride as an antimigraine model drug. Int. J. Latest Res. Sci. Technol,, 2012, 1(2), 80-89.

[35] Pavan, K.G.; Prasad, G.S. Physicochemical properties of lamotrigine and its compatibility with various inactive ingredients to formulate lamotrigine orally disintegrating tablets. Int. J. Pharm. Biol. Arch., 2013, 4(1), 94-95.

[36] Pathan, I.B.; Nirkhea, S.R.; Bairagib, A. Insitu gel based on gellan gum as new carrier for nasal to brain delivery of venlafaxine hydrochloride: Invitro evaluation and invivo study. J. Chem., 2015, 7(9), 324-331.

[37] Kohda, Y.; Kobayashi, H.; Baba, Y.; Yuasa, H.; Ozeki, T.; Kanaya, Y. Controlled release of lidocaine hydrochloride from buccal mucosa adhesive films with solid dispersion. Int. J. Pharm., 1997, 158, 147-155. [http://dx.doi.org/10.1016/S0378-5173(97)00241-X]

[38] Jug, M.; Bećirević-Laćan, M. Influence of hydroxypropyl-beta-cyclodextrin complexation on piroxicam release from buccoadhesive tablets. Eur. J. Pharm. Sci., 2004, 21(2-3), 251-260 [http://dx.doi.org/10.1016/j.ejps.2003.10.029] [PMID: 14757497]

[39] Pagar, S.A.; Shinkar1, DM.; Saudagar, RB. Development and evaluation of insitu nasal mucoadhesive gel of metoprolol succinate by using 3 ${ }^{2}$ full factorial design. Int J. Pharm. Pharm. Sci., 2014, 6(11), 218-223.

[40] Patil, P.R.; Salve, V.K.; Thorat, R.U.; Shahi, S.R. Formulation and evaluation of ion-sensitive insitu nasal gel of zolmitriptan. Int J. Pharm. Pharm. Sci., 2015, 7(1), 478-486.

[41] Nandgude, T.; Thube, R.; Jaiswal, N.; Deshmukh, P.; Chatap, V.; Hire, N. Formulation and evaluation of pH induced in situ nasal gel of salbutamol sulphate. Int. J. Pharm. Sci. Nanotech., 2008, 1, 177-182.

[42] Arigela, B.; Garikipathi, P.; Vaida, A.P.; Nadikatha, A.; Sali, R. Formulation and evaluation of floating oral in situ gel of oflaxacin for stomach specific delivery. World J. Pharm. Pharm. Sci., 2015, 4(2), 1144-1156.

[43] Pathan, I.B.; Chudiwal, V.; Farooqui, I.; Shingare, P. Formulation design and evaluation of nasal insitu gel as a novel vehicle for azelastine hydrochloride. Int. J. Drug Deliv., 2013, 5(3), 284-290.

[44] Cai, Z.; Song, X.; Sun, F.; Yang, Z.; Hou, S.; Liu, Z. Formulation and evaluation of in situ gelling systems for intranasal administration of gastrodin. AAPS PharmSciTech., 2011, 12(4), 1102-1109.

[http://dx.doi.org/10.1208/s12249-011-9678-y] [PMID: 21879392]

[45] Suppes, T.; Brown, E.S.; McElroy, S.L.; Keck, P.E., Jr; Nolen, W.; Kupka, R.; Frye, M.; Denicoff, K.D.; Altshuler, L.; Leverich, G.S.; Post, R.M. Lamotrigine for the treatment of bipolar disorder: A clinical case series. J. Affect. Disord., 1999, 53(1), 95-98. [http://dx.doi.org/10.1016/S0165-0327(98)00077-9] [PMID: 10363672]

[46] Gohel, M.C.; Parikh, R.K.; Nagori, S.A.; Shah, S.N.; Dabhi, M.R. Preparation and evaluation of soft gellan gum gel containing paracetamol. Indian J. Pharm. Sci., 2009, 71(2), 120-124. [http://dx.doi.org/10.4103/0250-474X.54273] [PMID: 20336205]

[47] Denise, F.S. Xanthan gum: A versatile biopolymer for biomedical and technological applications. J. Appl. Polym. Sci., 2015, 132(23)

[48] Sun, L.; Yu, T.; Guo, J.; Zhang, Z.; Hu, Y.; Xiao, X.; Sun, Y.; Xiao, H.; Li, J.; Zhu, D.; Sai, L.; Li, J. The estrogenicity of methylparaben and ethylparaben at doses close to the acceptable daily intake in immature Sprague-Dawley rats. Sci. Rep., 2016, 6, 25173. [http://dx.doi.org/10.1038/srep25173] [PMID: 27121550]

[49] Manisha, R.; Bhavna, T.; Manjula, R. Insitu gel sustained nasal drug delivery. Int. J. Pharm. Sci. Res., 2015, 6(1), 4958-4966.

[50] Miller, S.C.; Donovan, M.D. Effect of poloxamer 407 gels on the miotic activity of pilocarpine nitrate in rabbits. Int. J. Pharm., 1982, 12, $142-152$.

[http://dx.doi.org/10.1016/0378-5173(82)90114-4]

[51] Khan, S. Review: Insitu gelling system. J. innovation Pharm. Biol. Sci., 2014, 1(2), 88-91.

[52] Kumar, M.V.; Aravindram, A.S.; Rohitash, K.; Gowda, D.V.; Parjanya, K. Formulation and evaluation of insitu gel of bromhexine hydrochloride for nasal delivery. Pharm. Sin., 2012, 3, 699-707.

[53] Hiremath, S.P.; Dasankoppa, F.S.; Nadaf, A.; Jamakandi, V.G.; Mulla, J.S.; Sreenivas, S.A.; Hasanpasha, N.S. Aezazahmed, Nanjundaswamy, NG. Formulation and evaluation of a novel insitu gum based ophthalmic drug delivery system of linezolid. Sci. Pharm., 2008, 76, 515-532.

[http://dx.doi.org/10.3797/scipharm.0803-17] 
[54] Patel, D.M.; Patel, D.K.; Patel, C.N. Formulation \& Evaluation of Floating Oral insitu Gelling system of Amoxicillin. Cario Int. Sch. Res. Network, 2011, 1, 1-8.

[55] Yellanki, SK.; Anna, B.; Krishan, MR. Preparation of ocular insitu gel for glaucoma treatment using isolated Forskolin from coleus forskoli Root. Int. J. Res. Dev. Pharm. Life Sci., 2016, 5(1), 1981-1985.

[56] Sherafudeen, S.P.; Vasantha, P.V. Development and evaluation of in situ nasal gel formulations of loratadine. Res. Pharm. Sci., 2015, 10(6), 466-476.

[PMID: 26779266]

[57] Choi, H.G.; Shim, C.K.; Kim, D.D. Development of in situ gelling and mucoadhesive acetaminophen liquid suppository. Int. J. Pharm., 1998, $165,33-44$. [http://dx.doi.org/10.1016/S0378-5173(97)00386-4]

[58] Harish, N.M.; Prabhu, P.; Charyulu, R.N.; Gulzar, M.A.; Subrahmanyam, E.V. Formulation and evaluation of insitu gels containing clotrimazole for oral candidiasis. Indian J. Pharm. Sci., 2009, 71(4), 421-427. [http://dx.doi.org/10.4103/0250-474X.57291] [PMID: 20502548]

[59] Chand, P.; Chand, P.; Pratibha, Gnanarajan G.; Kothiyal, P. In situ gel: A review. Indian J. Pharma. Biol. Res., 2016, 4(2), 11-19.

[60] Lei, S.; Cao, Qi, Z.; Zhang, Xinguo J. Preparation of ion activated insitu gelling system of scopolamine hydrobromide \& evaluation of its antimotion sickness efficiency. Acta Pharmacol. Sin., 2007, 28, 584-590. [http://dx.doi.org/10.1111/j.1745-7254.2007.00540.x] [PMID: 17376300]

[61] Mandal, S.; Thimmasetty, M.K.; Prabhushankar, G.; Geetha, M. Formulation and evaluation of an in situ gel-forming ophthalmic formulation of moxifloxacin hydrochloride. Int. J. Pharm. Investig., 2012, 2(2), 78-82. [http://dx.doi.org/10.4103/2230-973X.100042] [PMID: 23119236]

[62] Shinde, J.S.; Mali, K.K.; Dias, R.J.; Havaldar, V.D.; Mahajan, N.S. Insitu mucoadhesive nasal gels of metoclopramide hydrochloride: Preformulation and formulation studies. J. Pharm. Res., 2008, 1, 88-96.

[63] Edsman, K.; Carlfors, J.; Petersson, R. Rheological evaluation of poloxamer as an in situ gel for ophthalmic use. Eur. J. Pharm. Sci., 1998, $6(2), 105-112$.

[http://dx.doi.org/10.1016/S0928-0987(97)00075-4] [PMID: 9795025]

[64] Chelladurai, S.; Mishra, M.; Mishra, B. Design and evaluation of bioadhesive in-situ nasal gel of ketorolac tromethamine. Chem. Pharm. Bull. (Tokyo), 2008, 56(11), 1596-1599. [http://dx.doi.org/10.1248/cpb.56.1596] [PMID: 18981612]

[65] Carlfors, J.; Edsman, K.; Petersson, R.; Jörnving, K. Rheological evaluation of Gelrite in situ gels for ophthalmic use. Eur. J. Pharm. Sci., 1998, 6(2), 113-119. [http://dx.doi.org/10.1016/S0928-0987(97)00074-2] [PMID: 9795027]

[66] Mohan, E.C.; Kandukurni, J.M.; Allenki, V. Preparation and evaluation of insitu gels for ocular Drug Delivery. J. Pharm. Res., 2009, 2(6), 1089-1094.

[67] Makwana, S.B.; Patel, V.A.; Parmar, S.J. Development and characterization of in-situ gel for ophthalmic formulation containing ciprofloxacin hydrochloride. Results Pharma Sci., 2015, 6, 1-6. [http://dx.doi.org/10.1016/j.rinphs.2015.06.001] [PMID: 26949596]

[68] Humeed, M.D. Preparation and invitro characterisation of mucoadhesive polymeric microspheres as intranasal delivery systems. Eur. J. Pharm. Biopharm., 1997, 44, 53-60. [http://dx.doi.org/10.1016/S0939-6411(97)00101-X]

[69] Zaki, N.M.; Awad, G.A. Mortoda, N.D.; Elrady. SSA. Enhanced Bioavailabilty of metoclopramide Hydrochloride by intraasal administraton of a mucoadhesive insitu gel with modulated Rheological and Mucocilliary Transport. Eur. J. Pharm. Sci., 2007, 32(4-5), 296-230. [http://dx.doi.org/10.1016/j.ejps.2007.08.006] [PMID: 17920822]

[70] Kalia, Insitu Gelling System: A Review. J. Drug Discovery Ther., 2014, 4(4), 93-103.

[71] Madan, J.R.; Adokar, B.R.; Dua, K. Development and evaluation of in situ gel of pregabalin. Int. J. Pharm. Investig., 2015, 5(4), 226-233. [http://dx.doi.org/10.4103/2230-973X.167686] [PMID: 26682193]

[72] Jones, D.S.; Woolfson, A.D.; Brown, A.F.; Coulter, W.A.; McClelland, C.; Irwin, C.R. Design, characterisation and preliminary clinical evaluation of a novel mucoadhesive topical formulation containing tetracycline for the treatment of periodontal disease. J. Control. Release, 2000, 67(2-3), 357-368. [http://dx.doi.org/10.1016/S0168-3659(00)00231-5] [PMID: 10825567]

[73] Frankland, A.W.; Walker, S.R. A comparison of intranasal betamethasone valerate and sodium cromoglycate in seasonal allergic rhinitis. Clin. Allergy, 1975, 5(3), 295-300.

[http://dx.doi.org/10.1111/j.1365-2222.1975.tb01866.x] [PMID: 810268]

[74] Vibha, B. Insitu gel nasal drug delivery. Int. J. Pharma. Sci., 2014, 4(3), 577-580.

[75] Harris, A.S.; Hedner, P.; Vilhardt, H. Nasal administration of desmopressin by spray and drops. J. Pharm. Pharmacol., 1987, 39(11), 932-934.

[http://dx.doi.org/10.1111/j.2042-7158.1987.tb03131.x] [PMID: 2892918] 
[76] Rao, M.R.; Shelar, S.U. Controlled release of ion sensitive floating oral insitu gel of a prokinetic drug using gellan gum. Indian J. Pharm. Edu. Res., 2015, 49(2), 158-169. [http://dx.doi.org/10.5530/ijper.49.2.13]

[77] Lee, J.W.; Park, J.H.; Robinson, J.R. Bioadhesive-based dosage forms: the next generation. J. Pharm. Sci., 2000, 89(7), 850-866. [http://dx.doi.org/10.1002/1520-6017(200007)89:7<850::AID-JPS2>3.0.CO;2-G] [PMID: 10861586]

[78] Singh, R.M.; Kumar, A.; Pathak, K. Thermally triggered mucoadhesive in situ gel of loratadine: $\beta$-cyclodextrin complex for nasal delivery. AAPS PharmSciTech, 2013, 14(1), 412-424 [http://dx.doi.org/10.1208/s12249-013-9921-9] [PMID: 23358934]

[79] Mehta, M.R.; Surve, S.A.; Menon, M.S. Novel nasal insitu gelling system for treatment of sinusitis. Indian J. Pharm. Sci., 2009, 71(6), 721-722.

[80] Bhalerao, A.V.; Lonkar, S.L.; Deshkar, S.S.; Shirlokar, S.V.; Despandae, A.D. Nasal mucoadhesive insitu gel of Ondansetron hydrochloride. Indian J. Pharm. Sci., 2009, 71(6), 711-713.

[81] Shan, R.A.; Mehta, M.R.; Patel, D.M.; Patel, C.N. Design and Optimization of Mucoadhesive nasal in situ gel containing sodium cromoglycate using factorial design; Asian J. Pharm, 2011, pp. 65-74.

[82] Basu, S.; Bandyopadhyay, A.K. Development and characterization of mucoadhesive in situ nasal gel of midazolam prepared with Ficus carica mucilage. AAPS PharmSciTech, 2010, 11(3), 1223-1231. [http://dx.doi.org/10.1208/s12249-010-9477-x] [PMID: 20683687]

[83] Costa, P.; Sousa Lobo, J.M. Modeling and comparison of dissolution profiles. Eur. J. Pharm. Sci., 2001, $13(2)$, $123-133$. [http://dx.doi.org/10.1016/S0928-0987(01)00095-1] [PMID: 11297896]

[84] Mahajan, H.S.; Dinger, S.B. Design and Invitro evaluation of nanoemulsion for nasal delivery of artemether. Indian J. Nov. Drug Deliv., 2011, 3(4), 272-277.

[85] Sapra, P.; Patel, D.; Soniwala, M.; Chavda, J. Development and optimization of insitu periodontal gel containing levofloxacin for the treatment of periodontal disease. J. Sci. Innovation Res., 2013, 2(3), 608-627.

[86] Sanjay, R.; Jigar, V.; Vijay, P.; Dhaval, R. A review on in situ polymeric drug delivery system. Int. J. Drug Formulation Res., 2011, 2(4), 143-168.

[87] Galgatte, U.C.; Kumbhar, A.B.; Chaudhari, P.D. Development of in situ gel for nasal delivery: Design, optimization, in vitro and in vivo evaluation. Drug Deliv., 2014, 21(1), 62-73.

[http://dx.doi.org/10.3109/10717544.2013.849778] [PMID: 24191774]

[88] Ibrahim, M.M.; Sammour, O.A.; Hammad, M.A.; Megrab, N.A. In vitro evaluation of proniosomes as a drug carrier for flurbiprofen. AAPS PharmSciTech, 2008, 9(3), 782-790. [http://dx.doi.org/10.1208/s12249-008-9114-0] [PMID: 18587650]

[89] Smart, J.D.; Kellaway, S.W.; Worthigton, H.E. An invivo investigation of mucosa adhesive material for use in controlled drug delivery. J. Pharm. Phrmacol, 1984, 36, 259-299.

[90] Nair, A.S.; Vidhya, K.M.; Saranya, T.; Sreelakshmy, K.R.; Nair, S.C. Mucoadhesive buccal patch of cefixime trihydrate using biodegradable natural polymer. Int J. Pharm. Pharm. Sci., 2014, 6(6), 366-371.

[91] Khan, S.; Patil, K.; Bobade, N.; Yeole, P.; Gaikwad, R. Formulation of intranasal mucoadhesive temperature-mediated in situ gel containing ropinirole and evaluation of brain targeting efficiency in rats. J. Drug Target., 2010, 18(3), 223-234. [http://dx.doi.org/10.3109/10611860903386938] [PMID: 20030503]

[92] Khan, N.; Aqil, M. Ameeduzzafar, Imam, SS.; Ali, A. Development and evaluation of a novel in situ gel of sparfloxacin for sustained ocular drug delivery: Invitro and exvivo characterization. Pharm. Dev. Technol., 2015, 20(6), 662-669. [http://dx.doi.org/10.3109/10837450.2014.910807] [PMID: 24754411]

[93] Guadalupe, N.; Elizabeth, P.; Luis, M.; Nestor, M.; David, Q.; Adriana, G. Formulation and invitro, exvivo and invivo evaluation of elastic liposomes for transdermal delivery of ketorolac tromethamine. Int. J. Pharm., 2011, 3, 954-970.

[94] Prarekh, H.B.; Rishad, J.; Jivani, N.P.; Patel, L.D.; Makwana, A.; Karunal, S. Novel insitu polymeric drug delivery system- A Review. J. Drug Deliv. Ther., 2012, 2(5), 136-145.

[95] Jagdale, S.; Shewale, N.; Kuchekar, B.S. Optimization of thermoreversible in situ nasal gel of Timolol Maleate. Scientifica (Cairo), 2016, $2016,6401267$.

[http://dx.doi.org/10.1155/2016/6401267] [PMID: 27293975]

[96] Majithiya, R.J.; Ghosh, P.K.; Umrethia, M.L.; Murthy, R.S. Thermoreversible-mucoadhesive gel for nasal delivery of sumatriptan. AAPS PharmSciTech, 2006, 7(3), 67. [http://dx.doi.org/10.1208/pt070367] [PMID: 17025248]

[97] Bhandwalkar, M.J.; Avachat, A.M. Thermoreversible nasal in situ gel of venlafaxine hydrochloride: Formulation, characterization, and pharmacodynamic evaluation. AAPS PharmSciTech, 2013, 14(1), 101-110. [http://dx.doi.org/10.1208/s12249-012-9893-1] [PMID: 23229381]

[98] Sawant, D.; Dandagi, P.M.; Gadad, A.P. Formulation and evaluation of sparfloxacin emulsomes- loaded thermosensitive in situ gel for ophthalmic delivery. J. Sol-Gel Sci. Technol., 2016, 77(3), 654-665. 
[http://dx.doi.org/10.1007/s10971-015-3897-8]

[99] Zhu, L.; Ao, J.; Li, P. A novel in situ gel base of deacetylase gellan gum for sustained ophthalmic drug delivery of ketotifen: In vitro and in vivo evaluation. Drug Des. Devel. Ther., 2015, 9, 3943-3949. [PMID: 26251573]

[100] Cao, S.L.; Ren, X.W.; Zhang, Q.Z.; Chen, E.; Xu, F.; Chen, J.; Liu, L.C.; Jiang, X.G. In situ gel based on gellan gum as new carrier for nasal administration of mometasone furoate. Int. J. Pharm., 2009, 365(1-2), 109-115.

[http://dx.doi.org/10.1016/j.ijpharm.2008.08.042] [PMID: 18822361]

(C) 2017 Paul et al.

This is an open access article distributed under the terms of the Creative Commons Attribution 4. 0 International Public License (CC-BY 4. 0), a copy of which is available at: https://creativecommons. org/licenses/by/4. 0/legalcode. This license permits unrestricted use, distribution, and reproduction in any medium, provided the original author and source are credited. 